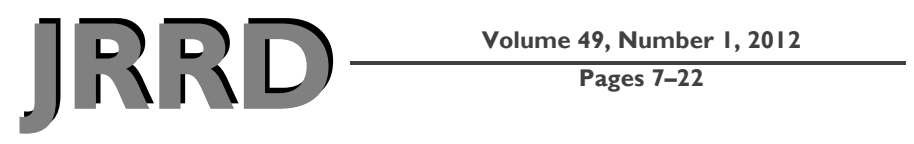

\title{
Dynamic stiffness and transmissibility of commercially available wheelchair cushions using a laboratory test method
}

\author{
Yasmin Garcia-Mendez, BS; ${ }^{1}$ Jonathan L. Pearlman, PhD; ${ }^{1-2 *}$ Rory A. Cooper, PhD; ${ }^{1-3}$ Michael L. Boninger, MD $^{1-3}$ \\ ${ }^{1}$ Human Engineering Research Laboratories and Department of Rehabilitation Science and Technology, University of \\ Pittsburgh, Pittsburgh, PA; ${ }^{2}$ Department of Veterans Affairs Rehabilitation Research and Development Service, Center \\ of Excellence in Wheelchairs and Related Technology, Pittsburgh, PA; ${ }^{3}$ Department of Physical Medicine and Rehabili- \\ tation and Department of Bioengineering, University of Pittsburgh, Pittsburgh, PA
}

\begin{abstract}
Evidence suggests that wheelchair (WC) users are exposed to unhealthy levels of vibration during WC use. Health risks associated with vibration exposure include vertebral disc degeneration and back pain, which may consequently decrease the function and independence of WC users. Some evidence suggests that the cushions used in WCs may amplify vibrations, although conclusive evidence has not been presented in the literature. This study evaluated and compared the transmissibility of commercially available WC cushions with two laboratory test methods: (1) direct measurement of transmissibility while human subjects propelled a WC over a road course with different cushions and (2) characterization of cushions with a material testing system (MTS) combined with mathematical models of the apparent mass of the human body. Results showed that although dynamic characterization of WC cushions is possible with an MTS, the results did not correlate well with the transmissibility obtained in the WC road course. Significant differences were found for transmissibility among the cushions tested, with the air-based cushions having lower transmissibility than the foam- or gel-based cushions.
\end{abstract}

Key words: dynamic stiffness, low back pain, manual wheelchair users, mathematical model, neck pain, transmissibility, vibration dose value, wheelchair, wheelchair cushions, wholebody vibration.

\section{INTRODUCTION}

Strine and Hootman estimate that 31 percent of the U.S. population has back and neck pain, the second lead- ing cause of disability and a major cause for low job satisfaction [1]. Among wheelchair (WC) users, the prevalence of back and neck pain is approximately double. Studies by Boninger et al. and Siddall et al. found that approximately 60 percent of people with disabilities who use WCs have back or neck pain [2-3]. They also found that 60 percent of their subjects visited the doctor because of their pain and 40 percent of them had to limit their daily activities. This increase in prevalence of back pain implies that WC users may have more exposure to risk factors for neck and back pain, such as inadequate postural support, stress, depression, vibration, and other physical and psychosocial factors [1,3]. However, little

Abbreviations: 3-D $=$ three-dimensional, ANOVA $=$ analysis of variance, ISO = International Organization for Standardization, MTS = material testing system, ODOF = one-degree-offreedom, $\mathrm{PSD}=$ power spectral density, $\mathrm{SAE}=$ Society of Automotive Engineers, TDOF = two-degree-of-freedom, VA = Department of Veterans Affairs, VAPHS = VA Pittsburgh Healthcare System, VDV = vibration dose value, $\mathrm{WBV}=$ whole-body vibration, $\mathrm{WC}=$ wheelchair, $\mathrm{WRC}=\mathrm{WC}$ road course.

*Address all correspondence to Jonathan L. Pearlman, PhD; Human Engineering Research Laboratories, 6425 Penn Ave, Suite 400, Pittsburgh, PA 15206; 412-822-3685; fax: 412-822-3699. Email: ilp46@pitt.edu

http://dx.doi.org/10.1682/JRRD.2011.02.0023 
research about the cause of neck and back pain in WC users has been conducted.

Because vibration exposure occurs in many occupational and recreational activities (such as sitting and driving), many studies have been conducted to determine its health consequences [4-7]. Vibration exposure that occurs while the whole body is supported by a vibrating surface, referred to as whole-body vibration (WBV), has been found to have an effect on humans' health, activities, and comfort [8]. The effects (either therapeutic or detrimental) of vibrations in an individual are related to the characteristics of the individual (physiological, psychosocial, and physical) and the vibrations (frequency, magnitude, duration, direction, etc.) [9]. For instance, low-magnitude, high-frequency WBV is effective at increasing bone mineral density [10]; WBV at frequencies lower than $0.5 \mathrm{~Hz}$ can cause motion sickness and discomfort [8]; and WBV exposure of long duration and at frequencies near the body's resonance frequency $(4-12 \mathrm{~Hz})$ transmits motion in excess of the input and can be detrimental to health [8].

Several studies have reported that WBV exposure as well as poor sitting posture are risk factors for low back pain [4-7,11-12]. Motor vehicle driving has been identified as the most common way to transmit WBV [13]. As a result, research in the field has led the International Organization for Standardization (ISO) to develop standards for assessing translational human exposure to WBV. These standards prescribe how to measure and assess vibration exposure and provide a "health guidance zone," which conveys the potential for health consequences based on the duration and amplitude of the WBV exposure [14].

Although most of the investigations of WBV exposure have been conducted on motor vehicle operators, it is logical that other seated individuals may be exposed to similar risks. WC users, for example, are also exposed to levels of vibration that enter the health guidance zone $[9,15-18]$. VanSickle et al. studied the dynamic reaction forces and moments applied to WC frames during laboratory and field tests [18]. Three important conclusions were drawn from this study: (1) both the WC and the user are exposed to infrequent but high-magnitude shocks; (2) the rider seems to absorb most of this energy; and (3) WC users are exposed to some high-impact vibrations of $50 \mathrm{~m} / \mathrm{s}^{2}$ or greater each day, which exceed the safety threshold indicated by the ISO standards. The authors suggested that proper manual WC suspension design could absorb a large amount of the energy from these shocks.
Other researchers have focused on the analysis of vibrations transmitted to the WC because of the texture of the roads. Wolf et al. found a positive correlation between the root-mean-square vertical vibration transmitted to the WC and the orientation and surface bevel size of concrete pavers [15]. Others have studied vibrations experienced by the WC user relative to the WC's characteristics. For instance, DiGiovine et al. found that ultralightweight WCs have better ergonomics and ride comfort than lightweight WCs [12]. Cooper et al. found that although suspension elements added to WCs can help reduce vibration exposure, peak accelerations in the frequency range harmful to humans are still transmitted [16].

Evidence exists that seat cushions may also influence the transmission of vibrations from the WC frame to the human body. For instance, in a study by DiGiovine et al. to evaluate the transmission of vibrations to everyday WC users, the authors found that, on average, the individuals' personal seating systems transmitted significantly more vibration than the seating system that performed best of the 16 combinations tested [9]. Although all the seating systems-human bodies tended to amplify vibrations in the frequency range harmful to humans as defined by ISO 2631-1 [14], this study suggests that cushion characteristics such as wear, age, material properties, and configuration significantly influence the transmission of vibrations. Other studies that compared the ability of seat cushions to minimize vibration exposure during manual WC propulsion support these results. For instance, Wolf et al. and DiGiovine et al. suggest that cushions made with a combination of foam and air transmit fewer impact and cyclic vibrations [19-20]. These studies also provide important findings about how vibrations are transmitted. They found that high-impact shocks were reduced whereas cyclic vibrations were amplified when accelerations at the head were compared with those measured under the seat cushion. These results demonstrated that the human body and seating system absorb the energy of high-impact vibrations, while cyclic vibrations in the same frequency range as the natural frequencies of the human body appear to be amplified [20].

Although the research cited previously provides some evidence that WBV exposure may contribute to back and neck pain among WC users, the individual role of the cushion, which would be the first line of protection against WBV, is not well understood. This is because in previous studies that assessed vibration exposure in WC users, measurements were collected below the seat 
cushion and in some cases at the head [9,19-20], which combines the cushion and subject into one mechanical unit. These methods attempt to represent WC cushion transmissibility by the input acceleration below the WC cushion under the output acceleration measured at the head, which underestimates the energy absorbed by the human body.

The dynamic response of the seating system to vibrations needs to be characterized independently of the human body to better understand whether harmful vibrations are entering the body (Figure 1). Methods for characterizing seat cushion transmissibility with a seated human subject have been defined in the literature [8,21]. However, these methods require a human subject to be seated on an indenter on top of the cushion while vibrations are applied to the cushion. Use of this method with subjects who do not have sensation could be dangerous.

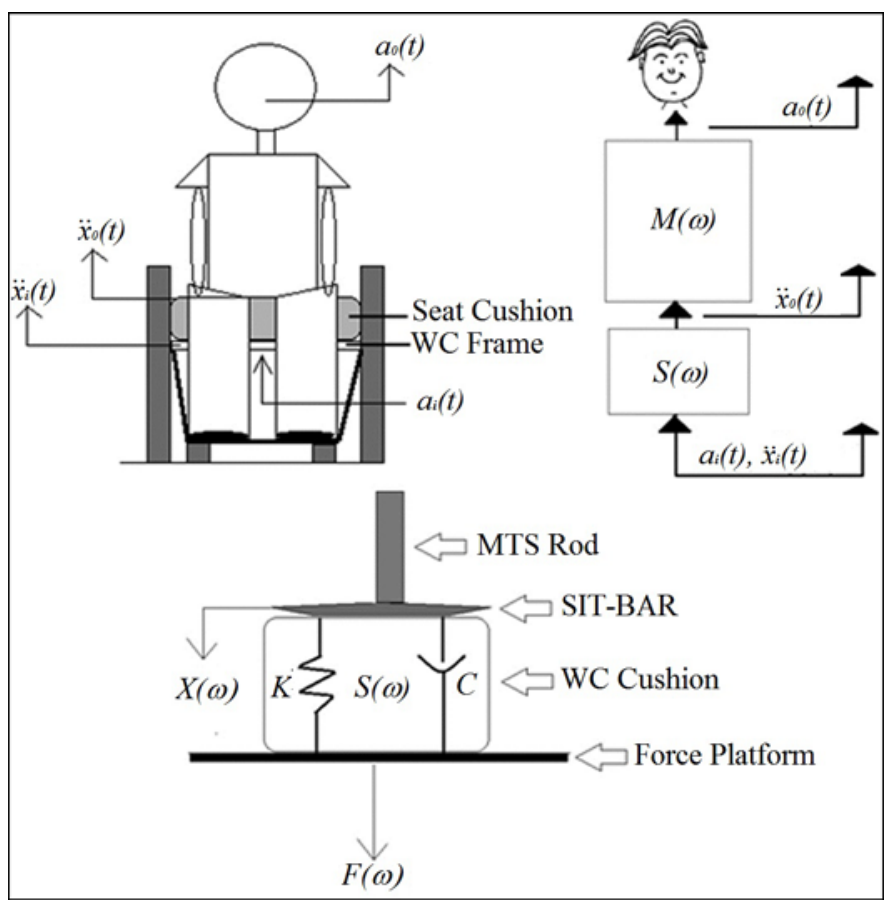

\section{Figure 1.}

Left, comparison of (1) independent dynamic characterization of the wheelchair (WC) cushion represented by input acceleration below cushion $\left(x_{i}(t)\right)$ under output acceleration at cushion surface $\left(x_{o}(t)\right)$; and (2) current methods to measure vibration transmissibility represented by input acceleration below cushion $\left(a_{i}(t)\right)$ under output acceleration at head $\left(a_{o}(t)\right)$. Right, free-body diagram of comparison on left. Bottom, dynamic stiffness model $S(\omega)$ of cushion when measured with SIT-BAR attached to material testing system (MTS) and force platform.
Methods have also been developed to characterize seated transmissibility with a laboratory technique that includes mathematical models to represent the dynamic response of the human body [22-23]. With this approach, the dynamic behavior of the WC cushions can be characterized with laboratory equipment without risk for individuals. If transmissibility measured with human subjects was shown to be similar to that measured according to a mathematical model, future work characterizing cushions could be performed without human subjects, thereby reducing the complexity and cost of these studies.

This work characterized and compared transmissibility of seat cushions in two ways: by directly measuring transmissibility while nondisabled individuals propelled a manual WC through a road course and by using a material testing system (MTS) to characterize cushion stiffness, which was then input into a mathematical model of the human-cushion system. We hypothesized that transmissibility measured with an MTS and in human subjects would be correlated, which would suggest that future characterization could be performed with the MTS alone. We also hypothesized that significant differences would exist in the transmissibility of commercially available WC cushions in the range of harmful vibrations (4-12 $\mathrm{Hz}$ ). This would be of great importance to clinicians when making decisions for cushion selection and prescription for individuals looking for greater comfort and reduced vibration effects (but minding pressure sore prevention).

\section{THEORY AND METHODS}

\section{Cushions}

Seven commercially available WC cushions were selected based on advice from clinicians from the Department of Veterans Affairs (VA) Pittsburgh Healthcare System (VAPHS) Wheelchair and Seating Clinic and the Center for Assistive Technology at the University of Pittsburgh. New WC cushions were borrowed from the VAPHS Wheelchair and Seating Clinic and are listed in Table 1 and shown in Figure 2.

Laboratory measurements of seated vibration transmissibility were undertaken with data from both human subjects and WC cushion dynamic characterization from the MTS (858 Bionix II, actuator model 244.12lf, 6 in. vertical stroke, pump model 505.11, MTS Systems Corporation; Eden Prairie, Minnesota). 
Table 1.

Description of seat cushions.

\begin{tabular}{lll}
\hline \multicolumn{1}{c}{ Model } & \multicolumn{1}{c}{ Manufacturer } & Description \\
\hline $\begin{array}{l}\text { Meridian Wave } \\
\text { ROHO HIGH PROFILE }\end{array}$ & Varilite; Seattle, Washington & Solid foam base and dual chamber of air-foam floatation. \\
ROHO LOW PROFILE & The ROHO Group; Belleville, Illinois \\
Jay J2 Deep Contour & $\begin{array}{l}\text { The ROHO Group; Belleville, Illinois } \\
\text { Sunrise Medical; Stourbridge, } \\
\text { United Kingdom }\end{array}$ & $\begin{array}{l}\text { Single compartment of high interconnected air cells. } \\
\text { Single compartment of low interconnected air cells. } \\
\text { Gel compartment over contoured foam base. }\end{array}$ \\
$\begin{array}{l}\text { Vector with Vicair Technology } \\
\text { The Comfort Company; Bozeman, } \\
\text { Montana }\end{array}$ & $\begin{array}{c}\text { Individual air cells inserted into cushion shell that can be } \\
\text { removed or added to adjust body positioning and pressure } \\
\text { distribution. }\end{array}$ \\
$\begin{array}{l}\text { Zoombang Protective Gear } \\
\text { with Foam }\end{array}$ & $\begin{array}{l}\text { Invacare; Elyria, Ohio (Pin-dot) } \\
\text { Invacare; Elyria, Ohio (Zoombang) }\end{array}$ & $\begin{array}{l}\text { Mat of double layer of capsules filled with viscoelastic polymer } \\
\text { over Invacare Comfort Mate Foam cushion. }\end{array}$ \\
\hline \hline
\end{tabular}
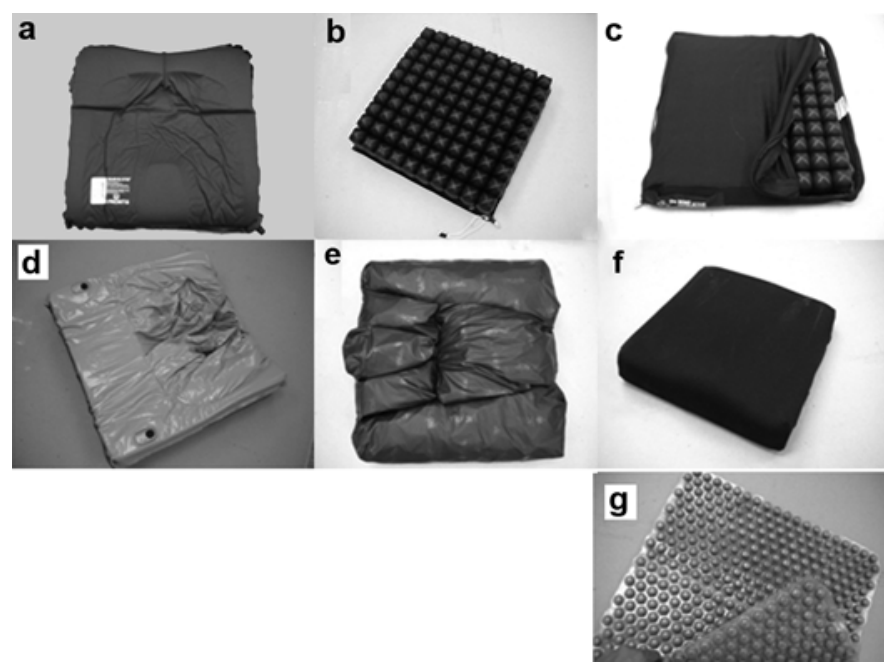

Figure 2.

Wheelchair cushions: (a) Meridian Wave, (b) ROHO HIGH PROFILE, (c) ROHO LOW PROFILE, (d) Jay J2 Deep Contour, (e) Vector with Vicair Technology, (f) Comfort Mate Foam, and (g) Zoombang Protective Gear with Foam.

\section{Dynamic Characterization of Wheelchair Cushions}

It is possible to estimate seated transmissibility by determining the seat's dynamic stiffness [8]. The dynamic stiffness, $S(\omega)$, of the seat is the complex ratio of the force to displacement in the frequency domain (expressed in hertz) and is given by Equation 1:

$$
S(\omega)=\frac{F(\omega)}{x(\omega)}
$$

where $F(\omega)$ is the force transmitted by the seat and $x(\omega)$ is the relative displacement of the seat cushion. $x(\omega)$ can also be expressed in terms of its second differentiation $\ddot{x}(\omega)$ (i.e., acceleration):

$$
x(\omega)=\omega^{-2} \ddot{x}(\omega) \quad .
$$

Therefore, the dynamic stiffness expressed in terms of the force transmitted by the seat and the acceleration recorded below $\left(\ddot{x}_{\mathrm{b}}(\omega)\right)$ and above $\left(\ddot{x}_{\mathrm{s}}(\omega)\right)$ the seat cushion is

$$
S(\omega)=\frac{F(\omega)}{\omega^{-2}\left[\ddot{x}_{s}(\omega)-\ddot{x}_{b}(\omega)\right]} .
$$

The dynamic stiffness can also be determined by making the indenter vibrate while the cushion is static [8]. The seat dynamic characterization with the moving indenter may be represented by the function

$$
S(\omega)=\frac{F(\omega)}{\omega^{-2} \ddot{x}_{s}(\omega)}=K+C \omega i
$$

where $K$ is the static stiffness and $C$ is the viscous damping of the seat. Using Equation 4, we can calculate the $K$ and $C$ for each cushion with curve-fitting methods. Note that $K$ and $C$ may vary based on the preload of the indenter.

The dynamic stiffness of each cushion in this study was determined by exposing each cushion to $100 \mathrm{~s}$ of random vibration $( \pm 4 \mathrm{~mm}$ maximum displacement, peakto-peak acceleration with a flat power spectral density [PSD] over the range $0.5-20.0 \mathrm{~Hz}$ ) under six different preload conditions (300-800 $\mathrm{N}$ in $100 \mathrm{~N}$ increments) with the MTS. The loads and vibrations were applied to 


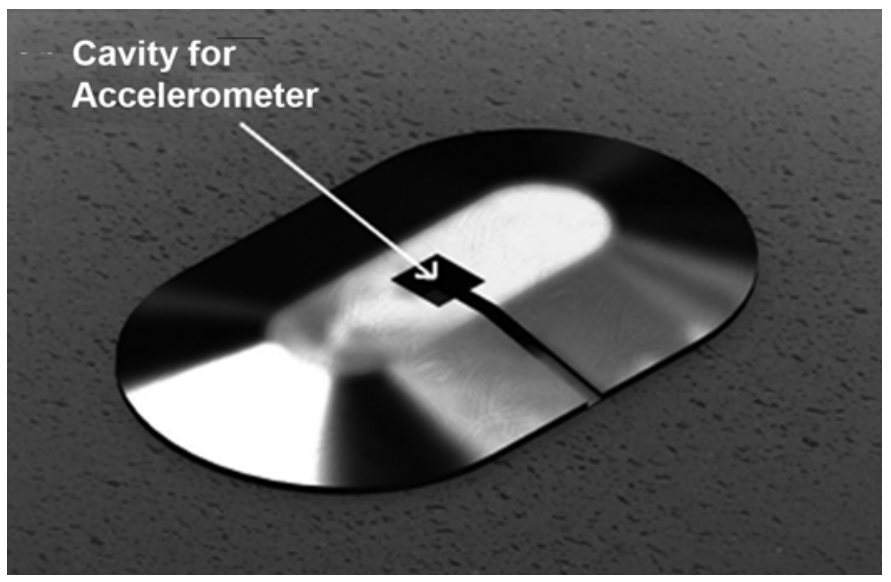

Figure 3.

SIT-BAR indenter used to load and vibrate wheelchair cushions.

the seat surface with a SIT-BAR indenter [8] (Figure 3) attached to the MTS actuator.

The reaction force below the cushion was measured with a 4550 Bertec force plate (Bertec Corporation; Columbus, Ohio) that was rigidly attached to the MTS base. Acceleration of the SIT-BAR was measured with a three-dimensional (3-D) accelerometer (CXL10LP3, \pm 10 g, 0-100 Hz, Moog Crossbow; Milpitas, California). Force and acceleration measurements were acquired at $200 \mathrm{~Hz}$ with an analog-to-digital acquisition card (DAQCardTM-6024E, National Instruments Corporation; Austin, Texas) and LabView Signal Express software (National Instruments Corporation). An algorithm was developed in MATLAB (The MathWorks, Inc; Natick, Massachusetts) to estimate the dynamic stiffness transfer function (Equation 4) from the acquired signals in the frequency domain and to compute the $K$ and $C$ dynamic parameters from the modulus of the dynamic stiffness: $\vec{S}=\sqrt{K^{2}+(C \omega)^{2}}$. Nonlinear least-squares curvefitting methods were used with an optimization algorithm (parameters were obtained with the MATLAB Curve Fit Toolbox).

Figure 4 shows the experimental setup, and the diagram on the bottom of Figure 1 conveys the mathematical representation of the system. Measurement of dynamic stiffness was performed three times per cushion at each preload.

\section{Measurement of Seated Transmissibility with Human Subjects}

Measurements of seated transmissibility were obtained for each seat cushion during field tests with 14 nondisabled

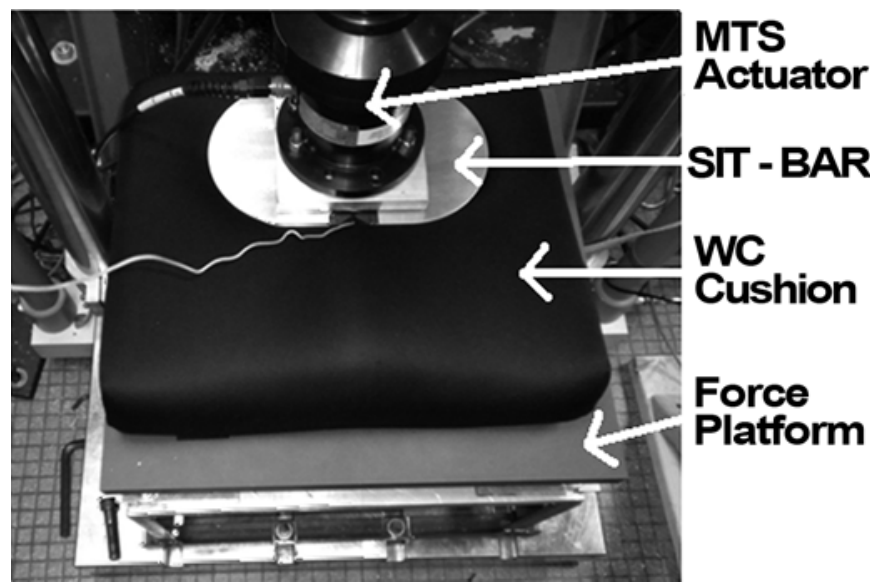

Figure 4.

Experimental configuration to measure dynamic stiffness of wheelchair (WC) cushions. MTS = material testing system.

human subjects. Informed consent and demographic information (sex, age, height, and weight) were gathered before each participant performed the field test (mean \pm standard deviation weight: $73.15 \pm 12.73 \mathrm{~kg}$ and height: $1.71 \pm$ $0.11 \mathrm{~m})$. Each person was asked to propel the same rigidframe WC (Quickie GP, Sunrise Medical; Stourbridge, United Kingdom) over a WC road course (WRC) to simulate activities of daily living while seated on each of the seven cushions. Each seat cushion was adjusted for each participant as indicated by the manufacturer. Measurements of accelerations at the WC-cushion interface and at the cushion-human interface were recorded using two 3-D accelerometers (Moog Crossbow) both located at the midline of the body under the ischial tuberosities. One accelerometer was placed under the cushion and attached to the WC frame using a 5/16 in.-thick aluminum seat pan (Figure 5). The second accelerometer was mounted in a SIT-BAR indenter and placed above the cushion for the subject to sit on (Figure 5). The SIT-BAR and seat-pan instrumentation were positioned and aligned as defined in ISO 2631-1 and ISO 10326-1 [14,24]. Data acquisition was performed using the same equipment and at the same frequency as described in the previous MTS section.

The WRC was created to replicate obstacles that WC users encounter in activities of daily living [17-18]. Obstacles included in the WRC were two $5 \mathrm{~cm}$ curb descents, a dimple strip mat, three sine-wave bumps (2.5, 5.0 , and $7.5 \mathrm{~cm}$, respectively), a simulated door threshold, industrial carpet, and a rumble bump mat. The WRC and the obstacles are shown in Figure 6. 


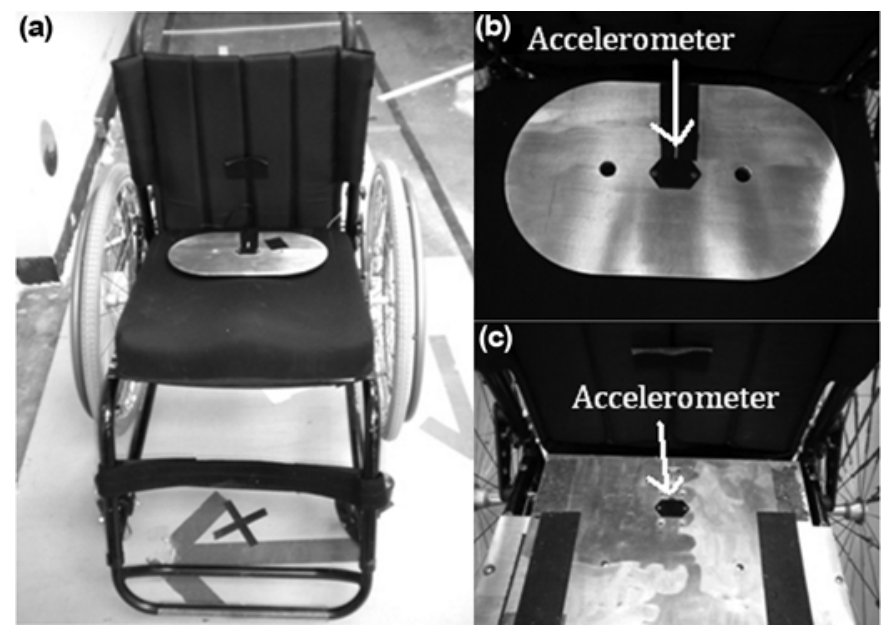

\section{Figure 5.}

(a) Manual wheelchair (WC) with Comfort Mate Foam cushion and SIT-BAR. (b) SIT-BAR with accelerometer attached. (c) Aluminum pan attached to WC frame with fixed accelerometer.

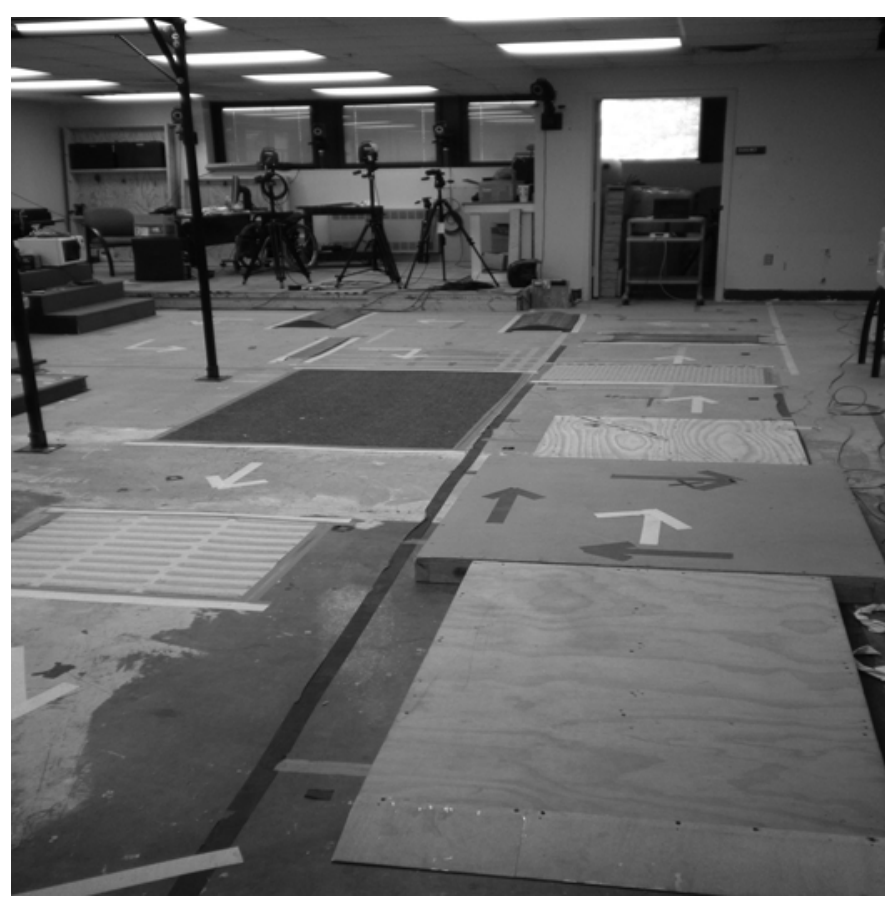

Figure 6.

Wheelchair road course.

Individuals propelled the WC in their most comfortable erect posture and at their self-selected velocity. The trial was repeated three times by every subject for each of the seven randomly presented cushions. The participants were allowed to rest or get out of the WC between trials.
Prior to data collection, each subject was trained in the WRC at least once to familiarize them with the obstacles.

Figure 1 shows the WC-seat-human system for this experiment. Seated transmissibility was calculated by the given equation:

$$
T(\omega)=\frac{\ddot{x}_{o}(\omega)}{\ddot{x}_{i}(\omega)},
$$

where $T(\omega)$ is the seated transmissibility, $\ddot{x}_{o}(\omega)$ is the output acceleration measured under the cushion, and $\ddot{x}_{i}(\omega)$ is the input acceleration measured above the cushion.

An algorithm written in MATLAB was developed to estimate the averaged transfer function (i.e., seated transmissibility) from the input and output acceleration signals for all the subjects and for each type of cushion at each sensor site (WC frame and seat surface).

\section{Mathematical Models of Seat Transmissibility}

Due to the dynamic interplay between the human body and the cushion, cushion vibration transmissibility from the MTS data must be calculated taking into account the response of the human body seated on it [8]. Wei and Griffin have developed different mathematical models for the human body that can be used to represent a person seated on a dynamic seating system (when vibrations occur) [23]. To predict seat vibration transmissibility without exposing human subjects to vibration, we used two mathematical models of the apparent mass of the human body (i.e., one-degree-of-freedom [ODOF] and two-degree-of-freedom [TDOF] models) in conjunction with the mechanical model of the seating system characterized previously and illustrated in the bottom of Figure 1. This methodology has already been shown to be appropriate for investigating seat dynamic performance from separate measurements of seat dynamic stiffness and the apparent mass of the human body [22]. The ODOF and TDOF models used to represent the cushionhuman body response to vertical vibrations are shown in Figure 7. Both models are represented by a support structure, $m$, and one or two mass-spring-damper systems (i.e., $K_{1}, C_{1}, m_{1}$ and/or $K_{2}, C_{2}, m_{2}$ ) that represent different parts of the human body supported by tissues. The model parameters $K_{1}, C_{1}, K_{2}, C_{2}, m, m_{1}$, and $m_{2}$ (obtained by Wei and Griffin from the analysis of measurements of the apparent masses of 60 persons [22-23]) are shown in Table 2. The $K$ and $C$ represent the seat dynamic parameters obtained from the characterization of each seat cushion in the first section of this study. 
(a)

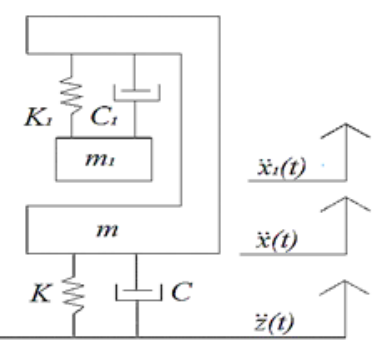

(b)

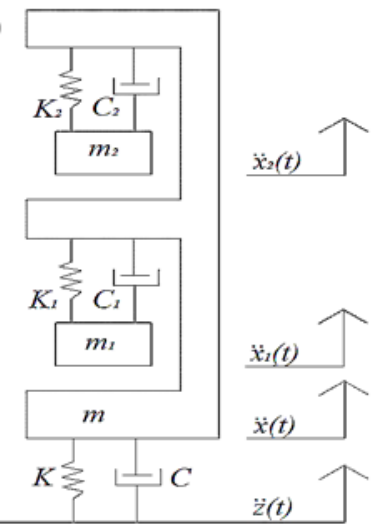

\section{Figure 7.}

(a) One-degree-of-freedom model of apparent mass of human body $\left(m_{1}\right)$. (b) Two-degree-of-freedom model of apparent mass of human body $\left(m_{1}\right.$ and $\left.m_{2}\right) . \ddot{x}(t), \ddot{x}_{1}(t)$, and $\ddot{x}_{2}(t)$ represent acceleration of each mass, respectively; and $\ddot{z}(t)$ acceleration and base of seat cushion.

The response of the ODOF model shown in Figure 7 is given by

$$
\begin{array}{r}
m_{1} \ddot{x}_{1}+K_{1}\left(x_{1}-x\right)+C_{1}\left(\dot{x}_{1}-\dot{x}\right)=0 \text { and } \\
m_{1} \ddot{x}_{1}+m \ddot{x}=K(z-x)+C(\dot{z}-\dot{x}) ;
\end{array}
$$

and the response of the TDOF model also shown in Figure $\mathbf{7}$ is given by

$$
\begin{gathered}
m_{1} \ddot{x}_{1}+K_{1}\left(x_{1}-x\right)+C_{1}\left(\dot{x}_{1}-\dot{x}\right)=0, \\
m_{2} \ddot{x}_{2}+K_{2}\left(x_{2}-x\right)+C_{2}\left(\dot{x}_{2}-\dot{x}\right)=0, \quad \text { and } \\
m \ddot{x}+m_{1} \ddot{x}_{1}+m_{2} \ddot{x}_{2}=K(z-x)+C(\dot{z}-\dot{x}) .
\end{gathered}
$$

The transmissibility of the seat cushion is given by the magnitude of the transfer function, $|H(\omega)|$, which can be derived from Equations $\mathbf{6}$ and $\mathbf{7}$ for the ODOF model [22] by

$$
\left|H_{\mathrm{ODOF}}(\omega)\right|=\left|\frac{\ddot{x}(\omega)}{\ddot{z}(\omega)}\right|=\left|\frac{(A+B i)}{(D+E i)}\right|=\sqrt{\frac{\left(A^{2}+B^{2}\right)}{\left(D^{2}+E^{2}\right)}} ;
$$

and from Equations $\mathbf{8}$ to $\mathbf{1 0}$ for the TDOF model by

$$
\left|H_{\mathrm{TDOF}}(\omega)\right|=\left|\frac{(F+G i)}{\{(H+L)+(M+N) i\}}\right|=\sqrt{\frac{\left(F^{2}+G^{2}\right)}{(H+L)^{2}+(M+N)^{2}}},
$$

where $A, B, D, E, F, G, H, L, M$, and $N$ are the polynomials of Equations 11 and 12 as defined in Figure 8 and simplified in the previous equations to improve readability.

For the ODOF model only, the mass was changed according to the averaged assumed sitting weight for all the subjects in the second section of this study. In other words, the term $\left(m+m_{1}\right)$ of the polynomial $D$ was made equal to 75 percent of the average total weight for all the subjects, as indicated in a previously cited study [23].

\section{Vibration Dose Value of Wheelchair Cushions}

Vibration dose value (VDV) is a vibration evaluation method defined by ISO 2631-1 [14] that is sensitive and useful for evaluating transient vibrations with occasional shocks. The VDV unit is meters per second to the power of 1.75 and is defined as

$$
\mathrm{VDV}=\left\{\int_{0}^{T}\left[a_{w}(t)\right]^{4} d t\right\}^{\frac{1}{4}},
$$

where $a_{w}(t)$ is the instantaneous frequency-weighted acceleration and $T$ is the duration of the measurement.

Vibration frequency content and axis have different effects on health than on comfort, perception, and motion sickness. To appropriately evaluate the effects of vertical vibrations on the health of seated humans, we applied a frequency-weighting filter as indicated by ISO 2631-1 [14] to the measured input and output accelerations before VDVs were estimated for both vibration measurements. The input and output accelerations were collected at the WC frame below the cushion and between the person and the cushion with the SIT-BAR during the WRC test. The transmissibility of each cushion was calculated with the VDV as defined in Equation 14:

$$
\mathrm{T}=\frac{\mathrm{VDV}_{\mathrm{o}}}{\mathrm{VDV}_{\mathrm{i}}}
$$

where $\mathrm{VDV}_{\mathrm{i}}$ is the VDV estimated with the input acceleration data and $\mathrm{VDV}_{\mathrm{o}}$ is the VDV estimated with the output acceleration data, both estimated over the entire WRC. 
Table 2.

Parameters of one-degree-of-freedom (ODOF) model and two-degree-of-freedom (TDOF) model of apparent mass of human body.

\begin{tabular}{lccccccc}
\hline Mathematical Model & $\boldsymbol{K}_{\mathbf{1}} \mathbf{( N / \mathbf { m } )}$ & $\left.\boldsymbol{C}_{\mathbf{1}} \mathbf{( N s} / \mathbf{m}\right)$ & $\boldsymbol{K}_{\mathbf{2}} \mathbf{( N / \mathbf { m } )}$ & $\boldsymbol{C}_{\mathbf{1}}(\mathbf{N s} / \mathbf{m})$ & $\boldsymbol{m} \mathbf{( k g})$ & $\boldsymbol{m}_{\mathbf{1}} \mathbf{( k g )}$ & $\boldsymbol{m}_{\mathbf{2}}(\mathbf{k g})$ \\
\hline ODOF & 44,130 & 1,485 & - & - & 7.8 & 43.4 & - \\
TDOF & 35,776 & 761 & 38,374 & 458 & 6.7 & 33.4 & 10.7 \\
\hline \hline
\end{tabular}

\section{Statistical Analysis}

After testing for normality, we performed two statistical analyses with repeated measures one-way analysis of variance (ANOVA) to evaluate whether differences existed (1) in the measured and estimated ODOF and TDOF transmissibility for all the seating systems and (2) in the estimated VDV transmissibility for all the seating systems. If significant differences were present, a Sidak post hoc analysis was performed for each ANOVA. Additionally, a correlation analysis was performed between predicted transmissibility obtained with the ODOF and TDOF models and the measured values of transmissibility with the WRC test.

\section{RESULTS}

\section{Dynamic Characterization of Wheelchair Cushions}

Figure 9 shows the measured modulus of the dynamic stiffness, $\vec{S}=\sqrt{K^{2}+(C \omega)^{2}}$, of the seven seating systems for all the preloads (300-800 N). All curves of the modulus of the dynamic stiffness over the range of loads (300-800 N) were fitted within the 95 percent goodness of fit to estimate stiffness and damping values. The estimated stiffness and the damping parameters for the seven different seating systems are shown in Table 3. All the cushions show increases in the stiffness and damping characteristics with increments in the preload. The Comfort Mate Foam (Invacare; Elyria, Ohio) and the Zoombang Protective Gear with Foam (Invacare) had the largest stiffness and damping values compared with the other cushions. The Jay J2 Deep Contour (Sunrise Medical) cushion had the lowest stiffness coefficients over the preload range, whereas the Meridian Wave (Varilite; Seattle, Washington) cushion showed the lowest damping coefficients. The former pair of seating systems also had the highest rate of increase in both the stiffness and damping parameters with increasing preloads. The Jay J2 Deep Contour and the Meridian Wave cushions had the lowest rates of increase of damping, and the Jay J2 Deep Contour and the ROHO LOW PROFILE (The ROHO Group; Belleville, Illinois) had the lowest rates of increase of stiffness.

\section{Measurement and Prediction of Cushion Transmissi- bility with Nondisabled Subjects and Mathematical Models}

Fourteen subjects participated in the WRC test to measure and estimate vibration transmissibility of seven

\begin{tabular}{|c|c|c|c|c|}
\hline $\begin{array}{l}A \\
=K K_{1}-\left(m_{1} K\right. \\
\left.+C C_{1}\right) \omega^{2}\end{array}$ & $\begin{array}{l}B \\
=\left(C_{1} K+C K_{1}\right) \omega \\
-m_{1} C \omega^{3}\end{array}$ & $\begin{array}{l}D \\
=(K \\
\left.-\left(m+m_{1}\right) \omega^{2}\right) K_{1} \\
+\left(m m_{1} \omega^{2}-K m_{1}\right. \\
\left.-C C_{1}\right) \omega^{2}\end{array}$ & $\begin{array}{l}E \\
=\left(K C_{1}+K_{1} C\right. \\
-\left(m_{1} C+m C_{1}\right. \\
\left.\left.+m_{1} C_{1}\right) \omega^{2}\right) \omega\end{array}$ & $F=K P_{1}-C P_{2} \omega$ \\
\hline$G=K P_{2}-C P_{1} \omega$ & $\begin{array}{l}H \\
=P_{1} P_{5}-P_{2} C \omega \\
-m_{1} K_{1} P_{3} \omega^{2}\end{array}$ & $\begin{array}{l}L \\
=m_{1} C_{1} C_{2} \omega^{4} \\
-\left(m_{2} K_{2} P_{4} \omega^{2}\right. \\
\left.-m_{2} C_{1} C_{2} \omega^{4}\right)\end{array}$ & $\begin{array}{l}N \\
=\left(m_{2} C_{2} P_{4} \omega^{3}\right. \\
\left.+m_{2} K_{2} C_{1} \omega^{3}\right)\end{array}$ & $\begin{array}{l}P_{1} \\
=m_{1} m_{2} \omega^{4}+K_{1} K_{2} \\
-\left(m_{1} K_{2}+m_{2} K_{1}\right. \\
\left.+C_{1} C_{2}\right) \omega^{2}\end{array}$ \\
\hline $\begin{array}{l}P_{2} \\
=\left(C_{1} K_{2}\right. \\
\left.+C_{2} K_{1}\right) \omega \\
-\left(m_{1} C_{2}\right. \\
\left.+m_{2} C_{1}\right) \omega^{3}\end{array}$ & $P_{3}=K_{2}-m_{2} \omega^{2}$ & $P_{4}=K_{1}-m_{1} \omega^{2}$ & \multicolumn{2}{|c|}{$P_{5}=K-m \omega^{2}$} \\
\hline
\end{tabular}

Figure 8.

Definitions of polynomials found in Equations $\mathbf{1 1}$ and $\mathbf{1 2 .}$ 


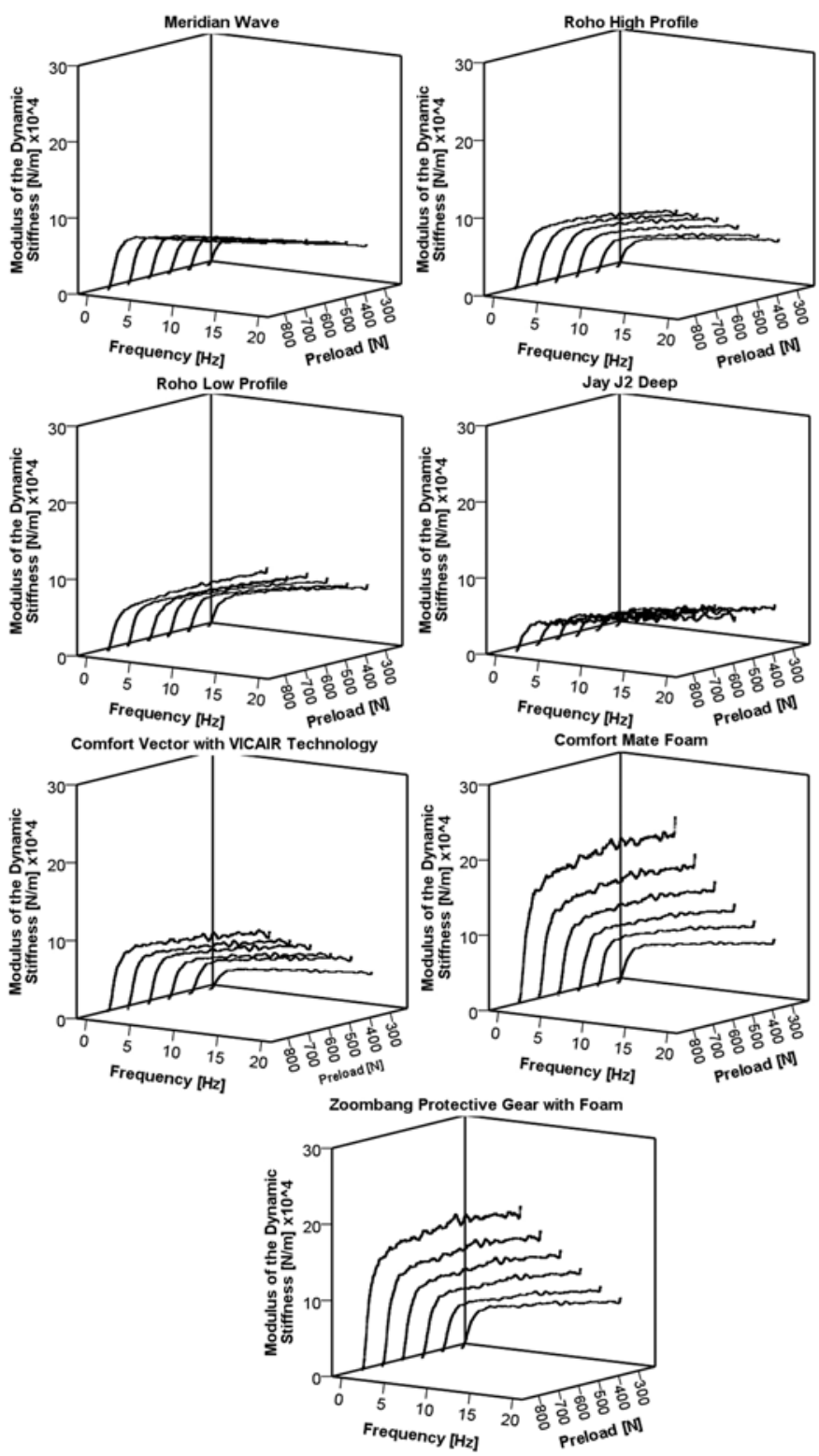

Figure 9.

Material testing system-measured modulus of dynamic stiffness for all preload forces of seven seating systems.

seating systems. Figure 10 shows the averaged measured seat transmissibility obtained in the WRC test of the seven seating systems compared with the ODOF and TDOF models of the seat transmissibility calculated with Equations 11 and 12. As can be seen from these figures, all seating systems amplified vibrations in a frequency range harmful to humans when measured or predicted with mathematical models. However, neither ODOF nor TDOF models accurately predicted measured seat trans- missibility during the WRC test. Both models overestimated seat transmissibility during WC propulsion at low frequency ranges (below $8 \mathrm{~Hz}$ ). In addition, the models predicted lower seat transmissibilities at frequencies between 8 and $12 \mathrm{~Hz}$, which underestimated measured seat transmissibilities during the WRC test.

An average PSD of the input vibration exposure of the subjects in the WRC test is shown in Figure 10 (bottom right corner). This figure shows that the spectral content is not the same throughout the frequency range from $0-20 \mathrm{~Hz}$ and differs from the flat spectrum the cushions are subjected to with the MTS. The PSD of the vibration exposure during the WRC test is higher at frequencies from $8-20 \mathrm{~Hz}$ than frequencies below $8 \mathrm{~Hz}$.

A summary of the maximum measured and predicted transmissibilities and corresponding frequencies for the seven seating systems are listed in Table 4. Neither mathematical model accurately predicted the maximum measured seat transmissibility. The ODOF model predicted that the Jay J2 Deep Contour and Meridian Wave have the highest maximum transmissibility and that the Comfort Mate Foam and Zoombang Protective Gear with Foam have the lowest maximum transmissibility. The TDOF model predicted different results. With this model, the Meridian Wave was identified as the cushion with the highest maximum transmissibility, whereas the ROHO LOW PROFILE, the Comfort Mate Foam, and the Zoombang Protective Gear with Foam were identified as the cushions with the lowest maximum transmissibility. These results differ from measured results, which identified the Comfort Mate Foam and the ROHO HIGH PROFILE as the cushions with the highest maximum transmissibility and the Jay J2 Deep Contour and the Vector with Vicair Technology as the cushions with the lowest maximum transmissibility.

Maximum seat transmissibility and frequency estimations from the ODOF and TDOF models were significantly higher than those measured in the WRC test. After logtransformation of data was performed for normality, we performed repeated-measures ANOVA with Sidak adjustment for multiple comparisons. We found significant effects of the methods used on both the transmissibility and the corresponding frequency $(F=24.127, d f=2, \rho<0.001$; and $F=13.352, d f=1.084, \rho=0.009$, respectively). Sidak post hoc analysis results showed a significant effect on transmissibility between measured data and ODOF model predictions ( $p=0.02, \alpha=0.05$ ) and between measured data and TDOF model predictions $(p=0.001, \alpha=0.05)$ and a 
Table 3.

Stiffness and damping parameters, $K$ (in N/m) and $C$ (in Ns/m), of seven wheelchair cushions over range of preloads (300-800 N).

\begin{tabular}{|c|c|c|c|c|c|c|c|c|c|c|c|c|c|c|}
\hline \multirow[t]{2}{*}{ Load (N) } & \multicolumn{2}{|c|}{$\begin{array}{c}\text { Vector with } \\
\text { Vicair }\end{array}$} & \multicolumn{2}{|c|}{$\begin{array}{l}\text { Meridian } \\
\text { Wave }\end{array}$} & \multicolumn{2}{|c|}{$\begin{array}{l}\text { ROHO HIGH } \\
\text { PROFILE }\end{array}$} & \multicolumn{2}{|c|}{$\begin{array}{c}\text { Jay J2 Deep } \\
\text { Contour }\end{array}$} & \multicolumn{2}{|c|}{$\begin{array}{l}\text { ROHO LOW } \\
\text { PROFILE }\end{array}$} & \multicolumn{2}{|c|}{$\begin{array}{c}\text { Zoombang } \\
\text { Protective Gear } \\
\text { with Foam }\end{array}$} & \multicolumn{2}{|c|}{$\begin{array}{c}\text { Comfort Mate } \\
\text { Foam }\end{array}$} \\
\hline & $K$ & $C$ & $K$ & $C$ & $K$ & $C$ & $K$ & $C$ & $K$ & $C$ & $K$ & $C$ & $K$ & $C$ \\
\hline$\overline{300}$ & 32,080 & 318 & 40,230 & 301 & 43,180 & 389 & 26,730 & 365 & 50,520 & 544 & 60,350 & 573 & 56,780 & 487 \\
\hline 400 & 50,340 & 478 & 50,500 & 322 & 51,740 & 475 & 27,940 & 406 & 56,730 & 602 & 74,160 & 727 & 76,140 & 696 \\
\hline 500 & 59,360 & 542 & 57,550 & 337 & 64,840 & 596 & 28,710 & 377 & 62,140 & 708 & 94,900 & 938 & 93,070 & 908 \\
\hline 600 & 71,580 & 665 & 64,760 & 372 & 77,390 & 688 & 36,890 & 508 & 64,460 & 835 & 116,900 & 1,132 & 115,500 & 1,149 \\
\hline 700 & 80,870 & 748 & 69,730 & 392 & 86,470 & 760 & 36,090 & 522 & 65,900 & 855 & 141,800 & 1,311 & 143,200 & 1,408 \\
\hline 800 & 95,040 & 840 & 76,010 & 397 & 94,220 & 834 & 39,970 & 571 & 68,600 & 1,015 & 174,900 & 1,507 & 183,200 & 1,689 \\
\hline $\begin{array}{l}\text { Rate of } \\
\text { Increase/100 N }\end{array}$ & 11,960 & 101 & 6,966 & 21 & 10,627 & 91 & 2,823 & 43 & 3,435 & 93 & 22,791 & 189 & 24,449 & 240 \\
\hline
\end{tabular}

significant effect on frequency between measured data and TDOF model predictions ( $p=0.03, \alpha=0.05$ ) and ODOF and TDOF model predictions ( $p=0.02, \alpha=0.05$ ).

\section{Vibration Dose Values of Wheelchair Cushions}

Figure 11 shows the VDV transmissibility measured in the WRC test. After log-transformation of data was performed for normality, we performed repeated-measures ANOVA with Sidak adjustment for multiple comparisons. We found significant effects of cushion on the VDV transmissibility $(F=7.219, d f=2.985, \rho=0.001)$. The Meridian Wave, Vector with Vicair Technology, and ROHO HIGH PROFILE cushions had the lowest transmissibility, whereas the Jay J2 Deep Contour, Comfort Mate Foam, and Zoombang Protective Gear with Foam had the highest transmissibility.

Figure 11 shows a box-plot of the VDV transmissibility and statistical groupings. Sidak post hoc analysis results revealed significant differences between (1) Jay J2 Deep Contour and Vector with Vicair technology ( $\rho=$ 0.003, $\alpha=0.05$ ), (2) Meridian Wave and Jay J2 Deep Contour ( $\rho<0.001, \alpha=0.05)$, (3) Meridian Wave and Zoombang Protective Gear with Foam $(\rho=0.014, \alpha=$ 0.05), (4) Meridian Wave and Comfort Mate Foam ( $\rho=$ 0.012, $\alpha=0.05$ ), and (5) ROHO HIGH PROFILE and Comfort Mate Foam $(\rho=0.03, \alpha=0.05)$.

\section{DISCUSSION}

Dynamic properties of seven different WC cushions were obtained with two laboratory test methods. Different stiffness and damping parameters (Table 3) among the WC cushions were found and are attributable to their construction materials. The Comfort Mate Foam and the
Zoombang Protective Gear with Foam cushions had the highest values of dynamic stiffness in contrast with the other seating systems, which have more complex constructions of air-foam, air-gel, or air. For instance, the air suspension properties of the ROHO HIGH PROFILE and ROHO LOW PROFILE cushions resulted in low stiffness values in contrast with the Comfort Mate Foam cushion. In the same way, the Meridian Wave cushion showed similar stiffness but lower damping to the air group cushions. This may be due to the low stiffness of its foam base component (lower than the foam cushion), which contrasted with the higher stiffness of the compartments of the ROHO cushions during compression. On the other hand, the Jay J2 Deep Contour cushion showed low values of stiffness and damping. The viscous gel contained in this cushion behaves like a solid during highimpact vibrations and is not good for suppressing vibrations [20]. It was observed that the gel slowly moved out of the area under the indenter, which may have decreased its dynamic stiffness. As preload increased, this effect was more noticeable and may have been a consequence of using the SIT-BAR as the indenter, although it is the industry standard for measuring vibration exposure under the seated individual. This effect occurs with WC users as well.

Figure 10 and Table 4 show that the ODOF and TDOF models failed to predict the seat transmissibility obtained in the WRC test. A possible reason for this could be that the ODOF and TDOF mathematical models were developed to fit seat transmissibility data obtained by directly vibrating human subjects with a vibrator table excited by random vibration with a flat acceleration PSD over the range 1-30 $\mathrm{Hz}$ [22], whereas the frequency content of the vibration produced by the WRC was variable. In addition, the WRC may not excite all modes of the 

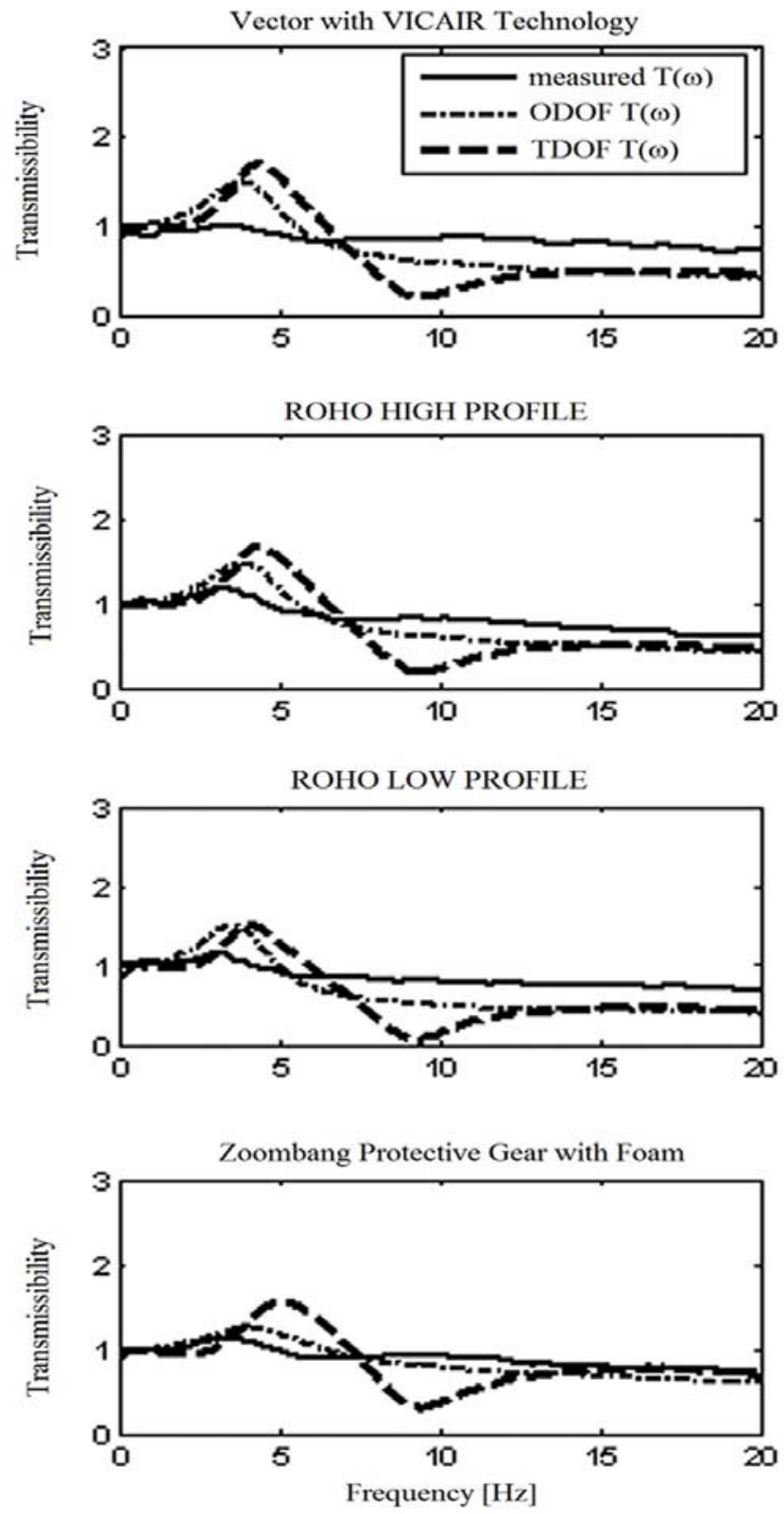
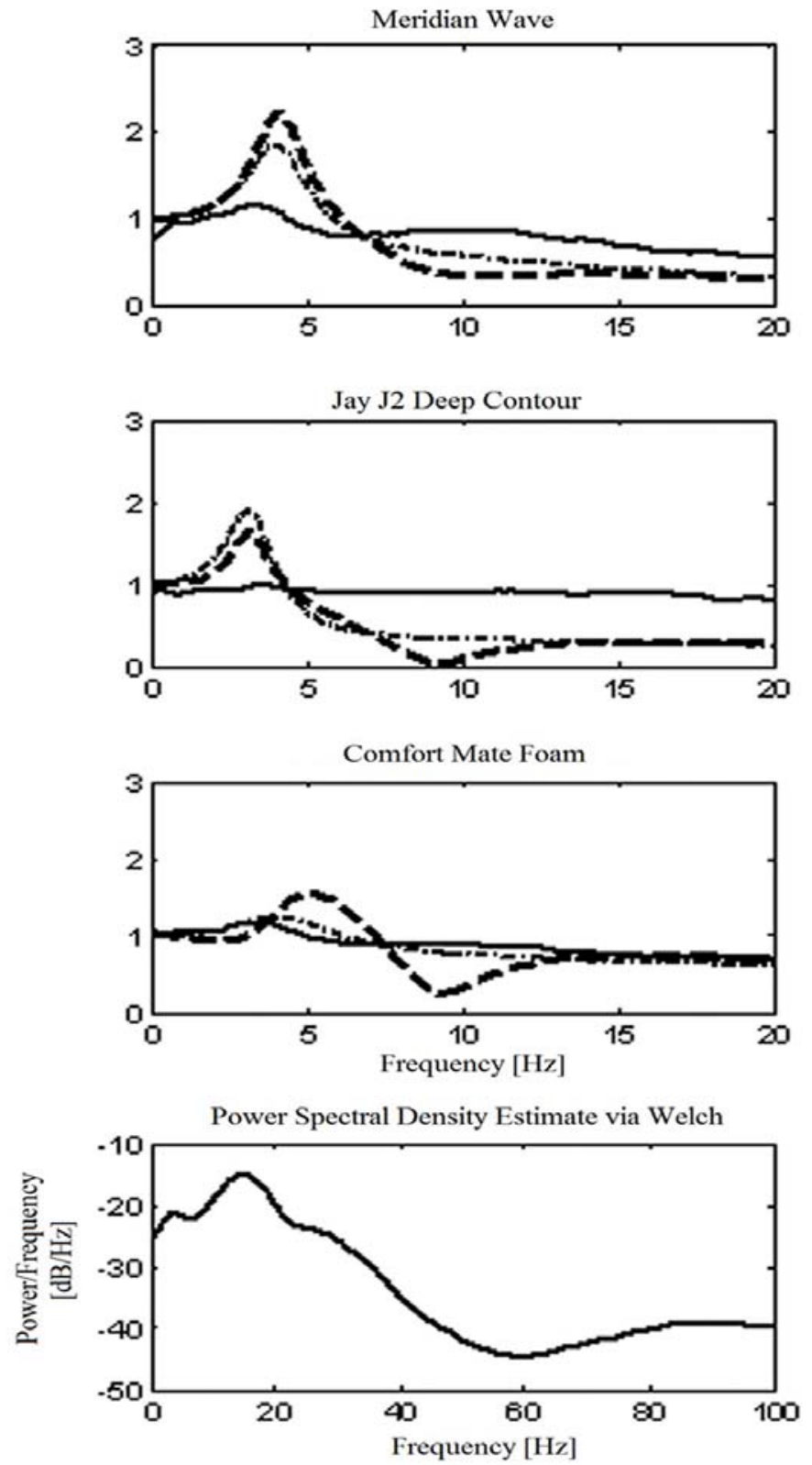

Figure 10.

Measured and predicted seat transmissibility for seven seating systems. Bottom-right corner: power spectral density of averaged input acceleration of wheelchair road course.

cushion, and those that are excited may not be excited with equal power. A PSD of the input vibration exposure of the subjects in the WRC test is shown in Figure 10 (bottom right corner). This figure shows that the spectral content is neither flat nor the same throughout the range from $0-20 \mathrm{~Hz}$. In addition to the PSD of the input vibration, other factors could affect seat transmissibility measures. For instance, subjects' body position (i.e., leg and back position, contact with backrest, contact with footrest, and arm support) has been show to affect seat transmissibility measurements [8]. Asking individuals to propel the WC may have had an important effect on their body position and load distribution on the seat, thereby affecting seat transmissibility measurements. For example, leaning forward off of the backrest has been shown to decrease the resonance frequency [8]. With vibrations 
Table 4.

Maximum transmissibility and corresponding frequency values obtained in WRC test and ODOF and TDOF models of seating systems.

\begin{tabular}{|c|c|c|c|c|c|c|}
\hline \multirow[b]{2}{*}{ Cushion } & \multicolumn{2}{|c|}{ WRC } & \multicolumn{2}{|c|}{ ODOF } & \multicolumn{2}{|c|}{ TDOF } \\
\hline & $\begin{array}{c}\text { Frequency } \\
\text { (Hz) }\end{array}$ & $\mathbf{T}$ & $\begin{array}{c}\text { Frequency } \\
\text { (Hz) }\end{array}$ & $\mathbf{T}$ & $\begin{array}{c}\text { Frequency } \\
\text { (Hz) }\end{array}$ & $\mathbf{T}$ \\
\hline$\overline{\mathrm{ROHO} \text { LOW PROFILE }}$ & 3.12 & 1.16 & 3.56 & 1.51 & 4.10 & 1.52 \\
\hline Jay J2 Deep Contour & 3.48 & 0.99 & 3.13 & 1.90 & 3.17 & 1.64 \\
\hline ROHO HIGH PROFILE & 3.37 & 1.18 & 3.88 & 1.48 & 4.40 & 1.67 \\
\hline Meridian Wave & 3.34 & 1.16 & 3.99 & 1.85 & 4.10 & 2.22 \\
\hline Vector with Vicair Technology & 3.27 & 1.01 & 3.87 & 1.50 & 4.35 & 1.69 \\
\hline Zoombang Protective Gear with Foam & 3.36 & 1.13 & 4.21 & 1.27 & 5.15 & 1.56 \\
\hline Comfort Mate Foam & 3.16 & 1.18 & 4.13 & 1.26 & 5.13 & 1.55 \\
\hline$\overline{\text { Mean } \pm \text { Standard Deviation }}$ & $3.30 \pm 0.13$ & $1.12 \pm 0.08$ & $3.82 \pm 0.37$ & $1.54 \pm 0.25$ & $4.34 \pm 0.68$ & $1.69 \pm 0.24$ \\
\hline
\end{tabular}

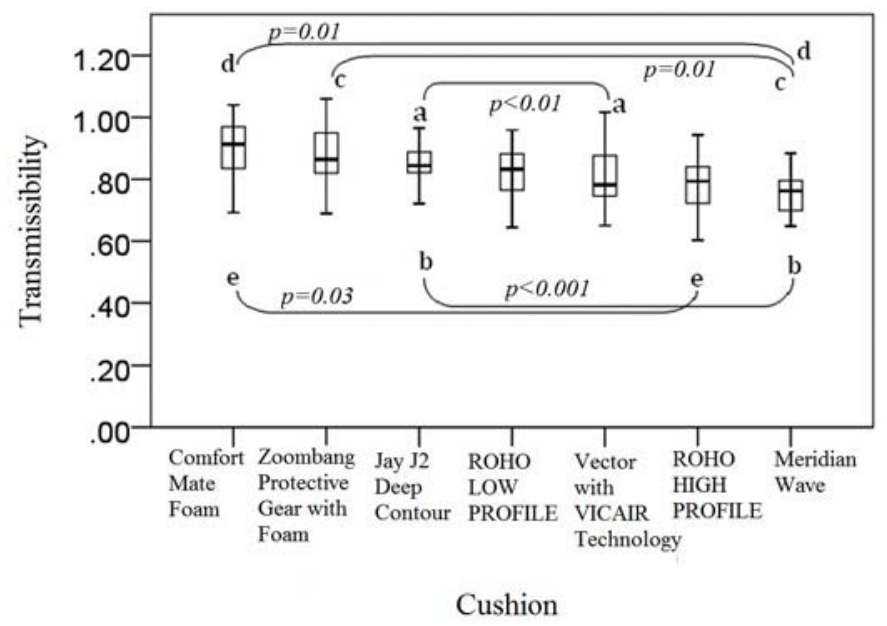

Figure 11.

Distribution of vibration dose value transmissibilities measured in wheelchair road course for seven seating systems. a, b, c, d, and e identify cushions with significant differences.

at a frequency just above resonance, subjects' leaning forward off of the backrest also caused significant decreases in seat transmissibility [8]. In addition, during the WRC test, the individuals had support for their feet, had to lean forward to ride the WC over obstacles (especially for the ramp and the sine-wave bumps), and had constant hand contact with the hand rim of the rear wheels. Furthermore, changes in trunk position during WC propulsion may also have a significant effect on the center of mass of the body (i.e., the total load applied on the seat). Because seat transmissibility is a function of both the apparent mass and the dynamic stiffness of the cushion, changes in the load applied on the seat cushion (as either a preload or the subject's apparent mass) may have significantly affected seat transmissibility measurements. An example of the effect of changes in preload on the dynamic stiffness of the cushion is clearly illustrated in Figure 9. Some studies have also found very little effect on vertical seat-to-head transmissibility measurements when vibrating the same subject without change of posture, whereas varying the body posture to a more erect position significantly increased the transmissibility at all frequencies above $3 \mathrm{~Hz}$. Table 4 shows significant decreases in maximum seat transmissibility and corresponding frequency during the WRC, which were probably caused by changes in body position. Furthermore, increasing user contact with the seat surface while the user "pulls-up" against the hand rim has been shown to decrease accelerations measured at the head [25].

Although pull-ups were not allowed in this study, subjects' use of the hand rim while traversing obstacles in the WRC may have had an effect on the amount of user contact with the seat surface, thereby changing the acceleration experienced at the user-seat interface. Additionally, individuals in the WRC propelled the WC at self-selected speeds that were not constant among all the participants. Variations in speed cause variations in vibration magnitude and frequency, which can affect the cushion-human system, thereby affecting seat transmissibility and resonance frequency measurements [8]. Griffin and Erdreich point out that increases in vibration magnitude produce decreases in seat transmissibility and resonance frequency [8]. The WRC includes obstacles that produce highmagnitude vibration impacts (e.g., the double curb descent shown in Figure 6), which may also contribute to reductions in maximum transmissibility and corresponding frequency. To measure seat vibration, we collected acceleration measurements at the human-cushion interface 
using the SIT-BAR to attach the accelerometers instead of the interface device developed by the Society of Automotive Engineers (SAE), the SAE pad [8], which was used for the development of the mathematical models. This may have had an effect on the cushion's surface deformation (especially for the gel cushion as it shifts the body down), the participant's position on the cushion, and the body contact area, thereby affecting transmissibility measurements. Unlike the SIT-BAR, the SAE pad is a thin "semi-rigid" ring that adjusts to the surface of the seat when loaded [8]. We preferred the SIT-BAR because its contour is similar to the human buttocks [8] and its rigid material and thickness allow it to be easily attached to the MTS. Finally, although the WC was not fit to participants as it would be to a client, the use of a single WC helped eliminate the effects of different WC types on the vibration transmissibility.

Although a drawback of this study was that the transmissibility measured with the MTS and on the WRC did not correspond well, we demonstrated the challenge of trying to accurately model WC propulsion with simple mathematical models. Future work will explore how to improve these models to better represent vibration transmission during WC propulsion and avoid use of disabled subjects for testing dynamic stiffness and measuring seat transmissibility. As a first step, we plan to develop a dynamic road simulator so subjects can be exposed to prescribed vibrations while acceleration measurements are collected above the cushion and at the head.

Significant differences were found between the VDV transmissibility measured on the WRC and the transmissibility from the models. These results may have important implications for WC cushion recommendations and selections for active WC users who are exposed to WBV on a daily basis. Figure 11 shows different transmissibility values among cushions estimated via the VDV method. Cushions with an air component had lower VDV than foam or gel cushions. For instance, the ROHO HIGH PROFILE and the Meridian Wave cushions had the lowest transmissibility values, while the Comfort Mate Foam and Jay J2 Deep Contour had the highest. No significant differences were found between the Comfort Mate Foam and the Zoombang Protective Gear with Foam ( $p=0.439, \alpha=0.05)$, suggesting that the Zoombang Protective Gear with Foam was not successful in reducing vibration exposure. The WRC results are consistent with prior results reported by DiGiovine et al. [20] and suggest that air-based cushions, or those with an air component, may be better at reducing vibration transmissibility than foam- or gel-based cushions.

It is important to note that the WRC test and VDV transmissibility methods produced different results. While VDV is an evaluation method whose output is a single value over the entire range of frequencies that does not provide information at specific frequencies, the WRC test is a means to simulate and measure vibrations over a range of frequencies and does not provide an assessment score. Moreover, the VDV method applies a weighted frequency filter to the acceleration data for VDV transmissibility estimation. The filter weights those accelerations at frequencies more dangerous for health.

Future research to characterize WC cushions should investigate the use of other indenters. For example, the rigid cushion loading indenter described by ISO 16840-2 may be a better representation of human anatomy than the SIT-BAR and may provide more accurate measurements of seat dynamic stiffness. Dynamic stiffness values are input parameters for mathematical models of humancushion systems. In addition to measurements of the dynamic response of WC cushions to vibration (such as those provided in this study), future studies should include measurements of the cushion's ability to absorb impacts related to curb descents and other obstacles as defined by ISO 16840-2 [26]. For instance, Sprigle et al. found different results than those found in this study regarding the ability of foam cushions to absorb vibrations and impact [27]. Yet Sprigle et al. used initial impact accelerations and rebounds as metrics of vibration and impact absorption rather than seat transmissibility. Their results showed that a 3 in.-flat foam cushion decreased initial impact acceleration during impact loading more than the other cushions in the test, suggesting greater dampening characteristics. Still the authors point out that more research is needed to relate results to clinical outcomes.

A final limitation of this study was the assumption that WC users can be represented by nondisabled subjects. It has been shown that disabled subjects have different biomechanics and body characteristics than nondisabled subjects, thereby affecting measurements of seat transmissibility. Future investigations should consider these factors when examining dynamic seat response to vibrations.

Future research should attempt to collect vibration exposure in the community for long durations. Combined with accurate measures of cushion transmissibility and comfort levels, this exposure data would be helpful in 
determining the health risks posed to the WC user and which cushions would reduce that risk. As a final recommendation, future work should also focus on objective measurements of ride comfort and back pain levels to explore their relationship with vibration exposure.

\section{CONCLUSIONS}

Selection of a WC cushion is critical to the health and safety of the WC user, especially if he or she has lost sensation. The most important variables driving the selection of a cushion are the pressure-relieving properties, weight, thermal properties, and ability to be cleaned. In this study, we demonstrated that transmissibility is another important characteristic to consider, as most cushions amplify vibrations (Table 4; $\mathrm{T}>1.0$ ). Air-based cushions outperformed the gel- and foam-based cushions and should be considered when selecting a cushion to help reduce vibration exposure or as a precaution against spinal pain.

Our transmissibility measurements calculated using the MTS and on the WRC did not correlate well, indicating that future work needs to focus on developing mathematical models of the body that better predict the dynamic response that occurs when propelling a WC. The development of such mathematical models will have important repercussions on WC cushion design and the prevention of health consequences when subjects test cushion dynamic stiffness.

\section{ACKNOWLEDGMENTS}

\author{
Author Contributions: \\ Study concept and design: J. L. Pearlman, R. A. Cooper, \\ M. L. Boninger. \\ Acquisition of data: Y. Garcia-Mendez. \\ Analysis and interpretation of data: Y. Garcia-Mendez. \\ Drafting of manuscript: Y. Garcia-Mendez. \\ Critical revision of manuscript for important intellectual content: \\ R. A. Cooper, M. L. Boninger. \\ Principal investigator: J. L. Pearlman. \\ Direct oversight of data collection and analysis: J. L. Pearlman. \\ Obtained funding: J. L. Pearlman.
}

Financial Disclosures: The authors have declared that no competing interests exist.

Funding/Support: This material is the result of work supported by VA Veterans Integrated Service Network 4 Competitive Pilot Project Fund (grant 02778), Career Development Award (grant B6673M), Wheelchair and Associated Rehabilitation Engineering (WaRE) VA
Center of Excellence (grant B6789C), and the Mexican National Council of Science and Technology Scholarship (register 212007).

Additional Contributions: The authors would like to thank the Human Engineering Research Laboratories staff and clinical coordinators. Institutional Review: The protocol was approved by the VAPHS Institutional Review Board (02778). Informed consent was provided by each participant.

Participant Follow-Up: The authors do not plan to inform participants of the publication of this study.

Disclaimer: The contents of this manuscript do not represent the views of the VA or the U.S. Government.

\section{REFERENCES}

1. Strine TW, Hootman JM. US national prevalence and correlates of low back and neck pain among adults. Arthritis Rheum. 2007;57(4):656-65. [PMID: 17471542]

http://dx.doi.org/10.1002/art.22684

2. Boninger ML, Cooper RA, Fitzgerald SG, Lin J, Cooper R, Dicianno B, Liu B. Investigating neck pain in wheelchair users. Am J Phys Med Rehabil. 2003;82(3):197-202.

[PMID: 12595772]

http://dx.doi.org/10.1097/01.PHM.0000054217.17816.DD

3. Siddall PJ, McClelland JM, Rutkowski SB, Cousins MJ. A longitudinal study of the prevalence and characteristics of pain in the first 5 years following spinal cord injury. Pain. 2003;103(3):249-57. [PMID: 12791431] http://dx.doi.org/10.1016/S0304-3959(02)00452-9

4. Hill TE, Desmoulin GT, Hunter CJ. Is vibration truly an injurious stimulus in the human spine? J Biomech. 2009; 42(16):2631-35. [PMID: 19880126] http://dx.doi.org/10.1016/j.jbiomech.2009.10.001

5. Seidel H, Heide R. Long-term effects of whole-body vibration: A critical survey of the literature. Int Arch Occup Environ Health. 1986;58(1):1-26. [PMID: 3522434] http://dx.doi.org/10.1007/BF00378536

6. Lings S, Leboeuf-Yde C. Whole-body vibration and low back pain: A systematic, critical review of the epidemiological literature 1992-1999. Int Arch Occup Environ Health. 2000;73(5):290-97. [PMID: 10963411] http://dx.doi.org/10.1007/s004200000118

7. Bakker EW, Verhagen AP, Van Trijffel E, Lucas C, Koes BW. Spinal mechanical load as a risk factor for low back pain: A systematic review of prospective cohort studies. Spine (Phila Pa 1976). 2009;34(8):E281-93.

[PMID: 19365237] http://dx.doi.org/10.1097/BRS.0b013e318195b257

8. Griffin M, Erdreich J. Handbook of human vibration. San Diego (CA): Academic Press Inc; 1990.

9. DiGiovine CP, Cooper RA, Fitzgerald SG, Boninger ML, Wolf EJ, Guo S. Whole-body vibration during manual wheelchair propulsion with selected seat cushions and back 
supports. IEEE Trans Neural Syst Rehabil Eng. 2003; 11(3):311-22. [PMID: 145187896]

http://dx.doi.org/10.1109/TNSRE.2003.816872

10. Totosy de Zepetnek JO, Giangregorio LM, Craven BC. Whole-body vibration as potential intervention for people with low bone mineral density and osteoporosis: A review. J Rehabil Res Dev. 2009;46(4):529-42. [PMID: 19882487] http://dx.doi.org/10.1682/JRRD.2008.09.0136

11. Corfman TA, Cooper RA, Fitzgerald SG, Cooper R. Tips and falls during electric-powered wheelchair driving: Effects of seatbelt use, legrests, and driving speed. Arch Phys Med Rehabil. 2003;84(12):1797-1802. [PMID: 14669186]

12. DiGiovine MM, Cooper RA, Boninger ML, Lawrence BM, VanSickle DP, Rentschler AJ. User assessment of manual wheelchair ride comfort and ergonomics. Arch Phys Med Rehabil. 2000;81(4):490-94. [PMID: 10768541] http://dx.doi.org/10.1053/mr.2000.3845

13. Harrison DD, Harrison SO, Croft AC, Harrison DE, Troyanovich SJ. Sitting biomechanics, part II: Optimal car driver's seat and optimal driver's spinal model. J Manipulative Physiol Ther. 2000;23(1):37-47. [PMID: 10658875] http://dx.doi.org/10.1016/S0161-4754(00)90112-X

14. ISO 2631-1. Mechanical vibration and shock. Evaluation of human exposure to whole-body vibrations. Part 1: General requirements. Geneva (Switzerland): International Organization for Standardization; 1997.

15. Wolf E, Pearlman J, Cooper RA, Fitzgerald SG, Kelleher A, Collins DM, Boninger ML, Cooper R. Vibration exposure of individuals using wheelchairs over sidewalk surfaces. Disabil Rehabil. 2005;27(23):1443-49. [PMID: 16418059] http://dx.doi.org/10.1080/09638280500264709

16. Cooper RA, Wolf E, Fitzgerald SG, Boninger ML, Ulerich $\mathrm{R}$, Ammer WA. Seat and footrest shocks and vibrations in manual wheelchairs with and without suspension. Arch Phys Med Rehabil. 2003;84(1):96-102. [PMID: 12589628] http://dx.doi.org/10.1053/apmr.2003.50069

17. VanSickle DP, Cooper RA, Boninger ML, DiGiovine CP. Analysis of vibrations induced during wheelchair propulsion. J Rehabil Res Dev. 2001;38(4):409-21. [PMID: 11563494]

18. VanSickle DP, Cooper RA, Boninger ML. Road loads acting on manual wheelchairs. IEEE Trans Rehabil Eng. 2000; 8(3):371-84. [PMID: 11001517]

http://dx.doi.org/10.1109/86.867879

19. Wolf EJ, Cooper MS, DiGiovine CP, Boninger ML, Guo S. Using the absorbed power method to evaluate effectiveness of vibration absorption of selected seat cushions during manual wheelchair propulsion. Med Eng Phys. 2004;26(9): 799-806. [PMID: 15564117] http://dx.doi.org/10.1016/j.medengphy.2004.06.005

20. DiGiovine CP, Cooper RA, Wolf EJ, Hosfield J, Corfman T. Analysis of vibration and comparison of four wheelchair cushions during manual wheelchair propulsion. Proceedings of the RESNA 2000 Annual Conference; 2000 Jun 28-Jul 2; Orlando, FL. Arlington (VA): RESNA Press; 2000. p. 242-44.

21. Fairley TE, Griffin MJ. A test method for the prediction of seat transmissibility. Society of Automotive Engineers. 1986;860046. http://dx.doi.org/10.4271/860046

22. Wei L, Griffin J. The prediction of seat transmissibility from measures of seat impedance. J Sound Vibration. 1998; 214(1):121-37. http://dx.doi.org/10.1006/jsvi.1998.1540

23. Wei L, Griffin MJ. Mathematical models for the apparent mass of the seated human body exposed to vertical vibration. J Sound Vibration. 1998;212(5):855-74.

http://dx.doi.org/10.1006/jsvi.1997.1473

24. ISO 10326-1. Mechanical vibration. Laboratory method for evaluating vehicle seat vibration. Part 1: Basic requirements. Geneva (Switzerland): International Organization for Standardization; 1992.

25. Requejo PS, Maneekobkunwong S, McNitt-Gray J, Adkins $\mathrm{R}$, Waters R. Influence of hand-rim wheelchairs with rear suspension on seat forces and head acceleration during curb descent landings. J Rehabil Med. 2009;41(6):459-66. [PMID: 19479159]

http://dx.doi.org/10.2340/16501977-0360

26. ISO 16840-2. Wheelchair seating. Part 2: Determination of physical and mechanical characteristics of devices intended to manage tissue integrity. Seat cushions. Geneva (Switzerland): International Organization for Standardization; 2007.

27. Sprigle S, Chung B, Meyer T. Assessment of the ISO impact damping test for wheelchair cushions. Assist Technol. 2010;22(4):236-44. [PMID: 21306069]

http://dx.doi.org/10.1080/10400435.2010.518581

Submitted for publication February 18, 2011. Accepted in revised form May 9, 2011.

This article and any supplementary material should be cited as follows:

Garcia-Mendez Y, Pearlman JL, Cooper RA, Boninger ML. Dynamic stiffness and transmissibility of commercially available wheelchair cushions using a laboratory test method. J Rehabil Res Dev. 2012;49(1):7-22.

http://dx.doi.org/10.1682/JRRD.2011.02.0023

ResearcherID: Yasmin Garcia-Mendez, BS: A-7497-2011

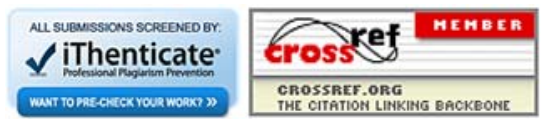





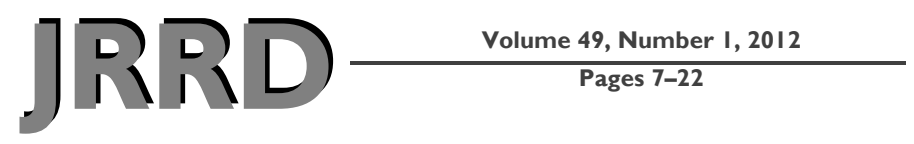

\title{
Dynamic stiffness and transmissibility of commercially available wheelchair cushions using a laboratory test method
}

\author{
Yasmin Garcia-Mendez, BS; ${ }^{1}$ Jonathan L. Pearlman, PhD; ${ }^{1-2 *}$ Rory A. Cooper, PhD; ${ }^{1-3}$ Michael L. Boninger, MD $^{1-3}$ \\ ${ }^{1}$ Human Engineering Research Laboratories and Department of Rehabilitation Science and Technology, University of \\ Pittsburgh, Pittsburgh, PA; ${ }^{2}$ Department of Veterans Affairs Rehabilitation Research and Development Service, Center \\ of Excellence in Wheelchairs and Related Technology, Pittsburgh, PA; ${ }^{3}$ Department of Physical Medicine and Rehabili- \\ tation and Department of Bioengineering, University of Pittsburgh, Pittsburgh, PA
}

\begin{abstract}
Evidence suggests that wheelchair (WC) users are exposed to unhealthy levels of vibration during WC use. Health risks associated with vibration exposure include vertebral disc degeneration and back pain, which may consequently decrease the function and independence of WC users. Some evidence suggests that the cushions used in WCs may amplify vibrations, although conclusive evidence has not been presented in the literature. This study evaluated and compared the transmissibility of commercially available WC cushions with two laboratory test methods: (1) direct measurement of transmissibility while human subjects propelled a WC over a road course with different cushions and (2) characterization of cushions with a material testing system (MTS) combined with mathematical models of the apparent mass of the human body. Results showed that although dynamic characterization of WC cushions is possible with an MTS, the results did not correlate well with the transmissibility obtained in the WC road course. Significant differences were found for transmissibility among the cushions tested, with the air-based cushions having lower transmissibility than the foam- or gel-based cushions.
\end{abstract}

Key words: dynamic stiffness, low back pain, manual wheelchair users, mathematical model, neck pain, transmissibility, vibration dose value, wheelchair, wheelchair cushions, wholebody vibration.

\section{INTRODUCTION}

Strine and Hootman estimate that 31 percent of the U.S. population has back and neck pain, the second lead- ing cause of disability and a major cause for low job satisfaction [1]. Among wheelchair (WC) users, the prevalence of back and neck pain is approximately double. Studies by Boninger et al. and Siddall et al. found that approximately 60 percent of people with disabilities who use WCs have back or neck pain [2-3]. They also found that 60 percent of their subjects visited the doctor because of their pain and 40 percent of them had to limit their daily activities. This increase in prevalence of back pain implies that WC users may have more exposure to risk factors for neck and back pain, such as inadequate postural support, stress, depression, vibration, and other physical and psychosocial factors [1,3]. However, little

Abbreviations: 3-D $=$ three-dimensional, ANOVA $=$ analysis of variance, ISO = International Organization for Standardization, MTS = material testing system, ODOF = one-degree-offreedom, $\mathrm{PSD}=$ power spectral density, $\mathrm{SAE}=$ Society of Automotive Engineers, TDOF = two-degree-of-freedom, VA = Department of Veterans Affairs, VAPHS = VA Pittsburgh Healthcare System, VDV = vibration dose value, $\mathrm{WBV}=$ whole-body vibration, $\mathrm{WC}=$ wheelchair, $\mathrm{WRC}=\mathrm{WC}$ road course.

*Address all correspondence to Jonathan L. Pearlman, PhD; Human Engineering Research Laboratories, 6425 Penn Ave, Suite 400, Pittsburgh, PA 15206; 412-822-3685; fax: 412-822-3699. Email: ilp46@pitt.edu

http://dx.doi.org/10.1682/JRRD.2011.02.0023 
research about the cause of neck and back pain in WC users has been conducted.

Because vibration exposure occurs in many occupational and recreational activities (such as sitting and driving), many studies have been conducted to determine its health consequences [4-7]. Vibration exposure that occurs while the whole body is supported by a vibrating surface, referred to as whole-body vibration (WBV), has been found to have an effect on humans' health, activities, and comfort [8]. The effects (either therapeutic or detrimental) of vibrations in an individual are related to the characteristics of the individual (physiological, psychosocial, and physical) and the vibrations (frequency, magnitude, duration, direction, etc.) [9]. For instance, low-magnitude, high-frequency WBV is effective at increasing bone mineral density [10]; WBV at frequencies lower than $0.5 \mathrm{~Hz}$ can cause motion sickness and discomfort [8]; and WBV exposure of long duration and at frequencies near the body's resonance frequency $(4-12 \mathrm{~Hz})$ transmits motion in excess of the input and can be detrimental to health [8].

Several studies have reported that WBV exposure as well as poor sitting posture are risk factors for low back pain [4-7,11-12]. Motor vehicle driving has been identified as the most common way to transmit WBV [13]. As a result, research in the field has led the International Organization for Standardization (ISO) to develop standards for assessing translational human exposure to WBV. These standards prescribe how to measure and assess vibration exposure and provide a "health guidance zone," which conveys the potential for health consequences based on the duration and amplitude of the WBV exposure [14].

Although most of the investigations of WBV exposure have been conducted on motor vehicle operators, it is logical that other seated individuals may be exposed to similar risks. WC users, for example, are also exposed to levels of vibration that enter the health guidance zone $[9,15-18]$. VanSickle et al. studied the dynamic reaction forces and moments applied to WC frames during laboratory and field tests [18]. Three important conclusions were drawn from this study: (1) both the WC and the user are exposed to infrequent but high-magnitude shocks; (2) the rider seems to absorb most of this energy; and (3) WC users are exposed to some high-impact vibrations of $50 \mathrm{~m} / \mathrm{s}^{2}$ or greater each day, which exceed the safety threshold indicated by the ISO standards. The authors suggested that proper manual WC suspension design could absorb a large amount of the energy from these shocks.
Other researchers have focused on the analysis of vibrations transmitted to the WC because of the texture of the roads. Wolf et al. found a positive correlation between the root-mean-square vertical vibration transmitted to the WC and the orientation and surface bevel size of concrete pavers [15]. Others have studied vibrations experienced by the WC user relative to the WC's characteristics. For instance, DiGiovine et al. found that ultralightweight WCs have better ergonomics and ride comfort than lightweight WCs [12]. Cooper et al. found that although suspension elements added to WCs can help reduce vibration exposure, peak accelerations in the frequency range harmful to humans are still transmitted [16].

Evidence exists that seat cushions may also influence the transmission of vibrations from the WC frame to the human body. For instance, in a study by DiGiovine et al. to evaluate the transmission of vibrations to everyday WC users, the authors found that, on average, the individuals' personal seating systems transmitted significantly more vibration than the seating system that performed best of the 16 combinations tested [9]. Although all the seating systems-human bodies tended to amplify vibrations in the frequency range harmful to humans as defined by ISO 2631-1 [14], this study suggests that cushion characteristics such as wear, age, material properties, and configuration significantly influence the transmission of vibrations. Other studies that compared the ability of seat cushions to minimize vibration exposure during manual WC propulsion support these results. For instance, Wolf et al. and DiGiovine et al. suggest that cushions made with a combination of foam and air transmit fewer impact and cyclic vibrations [19-20]. These studies also provide important findings about how vibrations are transmitted. They found that high-impact shocks were reduced whereas cyclic vibrations were amplified when accelerations at the head were compared with those measured under the seat cushion. These results demonstrated that the human body and seating system absorb the energy of high-impact vibrations, while cyclic vibrations in the same frequency range as the natural frequencies of the human body appear to be amplified [20].

Although the research cited previously provides some evidence that WBV exposure may contribute to back and neck pain among WC users, the individual role of the cushion, which would be the first line of protection against WBV, is not well understood. This is because in previous studies that assessed vibration exposure in WC users, measurements were collected below the seat 
cushion and in some cases at the head [9,19-20], which combines the cushion and subject into one mechanical unit. These methods attempt to represent WC cushion transmissibility by the input acceleration below the WC cushion under the output acceleration measured at the head, which underestimates the energy absorbed by the human body.

The dynamic response of the seating system to vibrations needs to be characterized independently of the human body to better understand whether harmful vibrations are entering the body (Figure 1). Methods for characterizing seat cushion transmissibility with a seated human subject have been defined in the literature [8,21]. However, these methods require a human subject to be seated on an indenter on top of the cushion while vibrations are applied to the cushion. Use of this method with subjects who do not have sensation could be dangerous.

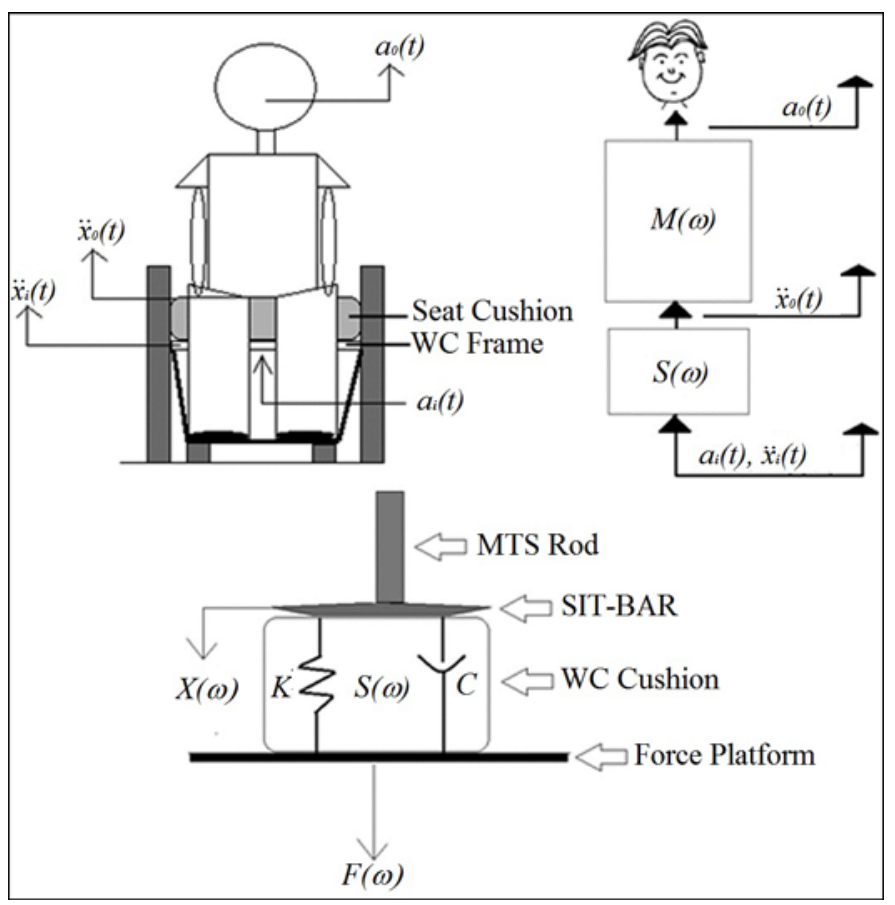

\section{Figure 1.}

Left, comparison of (1) independent dynamic characterization of the wheelchair (WC) cushion represented by input acceleration below cushion $\left(x_{i}(t)\right)$ under output acceleration at cushion surface $\left(x_{o}(t)\right)$; and (2) current methods to measure vibration transmissibility represented by input acceleration below cushion $\left(a_{i}(t)\right)$ under output acceleration at head $\left(a_{o}(t)\right)$. Right, free-body diagram of comparison on left. Bottom, dynamic stiffness model $S(\omega)$ of cushion when measured with SIT-BAR attached to material testing system (MTS) and force platform.
Methods have also been developed to characterize seated transmissibility with a laboratory technique that includes mathematical models to represent the dynamic response of the human body [22-23]. With this approach, the dynamic behavior of the WC cushions can be characterized with laboratory equipment without risk for individuals. If transmissibility measured with human subjects was shown to be similar to that measured according to a mathematical model, future work characterizing cushions could be performed without human subjects, thereby reducing the complexity and cost of these studies.

This work characterized and compared transmissibility of seat cushions in two ways: by directly measuring transmissibility while nondisabled individuals propelled a manual WC through a road course and by using a material testing system (MTS) to characterize cushion stiffness, which was then input into a mathematical model of the human-cushion system. We hypothesized that transmissibility measured with an MTS and in human subjects would be correlated, which would suggest that future characterization could be performed with the MTS alone. We also hypothesized that significant differences would exist in the transmissibility of commercially available WC cushions in the range of harmful vibrations (4-12 $\mathrm{Hz}$ ). This would be of great importance to clinicians when making decisions for cushion selection and prescription for individuals looking for greater comfort and reduced vibration effects (but minding pressure sore prevention).

\section{THEORY AND METHODS}

\section{Cushions}

Seven commercially available WC cushions were selected based on advice from clinicians from the Department of Veterans Affairs (VA) Pittsburgh Healthcare System (VAPHS) Wheelchair and Seating Clinic and the Center for Assistive Technology at the University of Pittsburgh. New WC cushions were borrowed from the VAPHS Wheelchair and Seating Clinic and are listed in Table 1 and shown in Figure 2.

Laboratory measurements of seated vibration transmissibility were undertaken with data from both human subjects and WC cushion dynamic characterization from the MTS (858 Bionix II, actuator model 244.12lf, 6 in. vertical stroke, pump model 505.11, MTS Systems Corporation; Eden Prairie, Minnesota). 
Table 1.

Description of seat cushions.

\begin{tabular}{lll}
\hline \multicolumn{1}{c}{ Model } & \multicolumn{1}{c}{ Manufacturer } & Description \\
\hline $\begin{array}{l}\text { Meridian Wave } \\
\text { ROHO HIGH PROFILE }\end{array}$ & Varilite; Seattle, Washington & Solid foam base and dual chamber of air-foam floatation. \\
ROHO LOW PROFILE & The ROHO Group; Belleville, Illinois \\
Jay J2 Deep Contour & $\begin{array}{l}\text { The ROHO Group; Belleville, Illinois } \\
\text { Sunrise Medical; Stourbridge, } \\
\text { United Kingdom }\end{array}$ & $\begin{array}{l}\text { Single compartment of high interconnected air cells. } \\
\text { Single compartment of low interconnected air cells. } \\
\text { Gel compartment over contoured foam base. }\end{array}$ \\
$\begin{array}{l}\text { Vector with Vicair Technology } \\
\text { The Comfort Company; Bozeman, } \\
\text { Montana }\end{array}$ & $\begin{array}{c}\text { Individual air cells inserted into cushion shell that can be } \\
\text { removed or added to adjust body positioning and pressure } \\
\text { distribution. }\end{array}$ \\
$\begin{array}{l}\text { Zoombang Protective Gear } \\
\text { with Foam }\end{array}$ & $\begin{array}{l}\text { Invacare; Elyria, Ohio (Pin-dot) } \\
\text { Invacare; Elyria, Ohio (Zoombang) }\end{array}$ & $\begin{array}{l}\text { Mat of double layer of capsules filled with viscoelastic polymer } \\
\text { over Invacare Comfort Mate Foam cushion. }\end{array}$ \\
\hline \hline
\end{tabular}
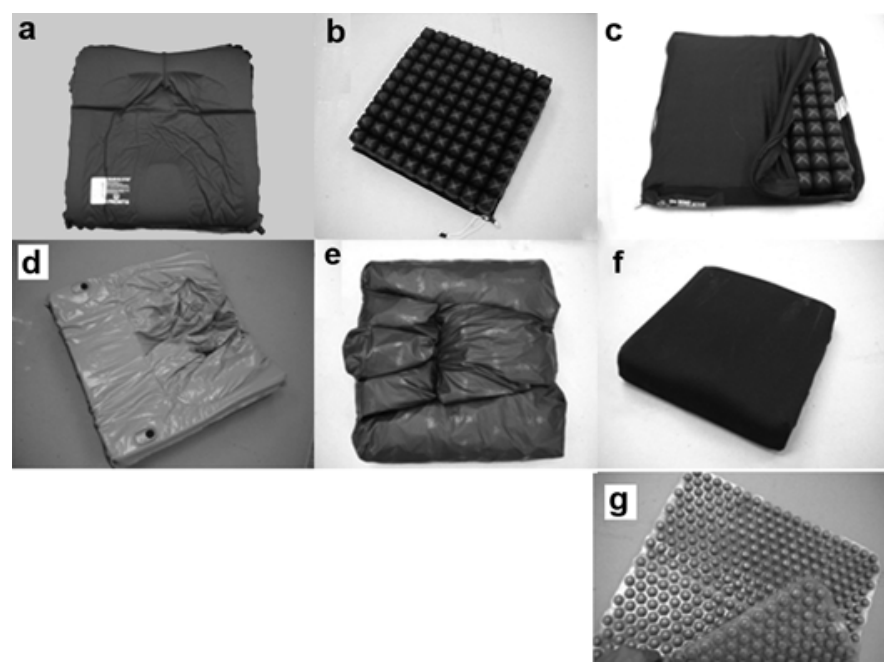

Figure 2.

Wheelchair cushions: (a) Meridian Wave, (b) ROHO HIGH PROFILE, (c) ROHO LOW PROFILE, (d) Jay J2 Deep Contour, (e) Vector with Vicair Technology, (f) Comfort Mate Foam, and (g) Zoombang Protective Gear with Foam.

\section{Dynamic Characterization of Wheelchair Cushions}

It is possible to estimate seated transmissibility by determining the seat's dynamic stiffness [8]. The dynamic stiffness, $S(\omega)$, of the seat is the complex ratio of the force to displacement in the frequency domain (expressed in hertz) and is given by Equation 1:

$$
S(\omega)=\frac{F(\omega)}{x(\omega)}
$$

where $F(\omega)$ is the force transmitted by the seat and $x(\omega)$ is the relative displacement of the seat cushion. $x(\omega)$ can also be expressed in terms of its second differentiation $\ddot{x}(\omega)$ (i.e., acceleration):

$$
x(\omega)=\omega^{-2} \ddot{x}(\omega) \quad .
$$

Therefore, the dynamic stiffness expressed in terms of the force transmitted by the seat and the acceleration recorded below $\left(\ddot{x}_{\mathrm{b}}(\omega)\right)$ and above $\left(\ddot{x}_{\mathrm{s}}(\omega)\right)$ the seat cushion is

$$
S(\omega)=\frac{F(\omega)}{\omega^{-2}\left[\ddot{x}_{s}(\omega)-\ddot{x}_{b}(\omega)\right]} .
$$

The dynamic stiffness can also be determined by making the indenter vibrate while the cushion is static [8]. The seat dynamic characterization with the moving indenter may be represented by the function

$$
S(\omega)=\frac{F(\omega)}{\omega^{-2} \ddot{x}_{s}(\omega)}=K+C \omega i
$$

where $K$ is the static stiffness and $C$ is the viscous damping of the seat. Using Equation 4, we can calculate the $K$ and $C$ for each cushion with curve-fitting methods. Note that $K$ and $C$ may vary based on the preload of the indenter.

The dynamic stiffness of each cushion in this study was determined by exposing each cushion to $100 \mathrm{~s}$ of random vibration $( \pm 4 \mathrm{~mm}$ maximum displacement, peakto-peak acceleration with a flat power spectral density [PSD] over the range $0.5-20.0 \mathrm{~Hz}$ ) under six different preload conditions (300-800 $\mathrm{N}$ in $100 \mathrm{~N}$ increments) with the MTS. The loads and vibrations were applied to 


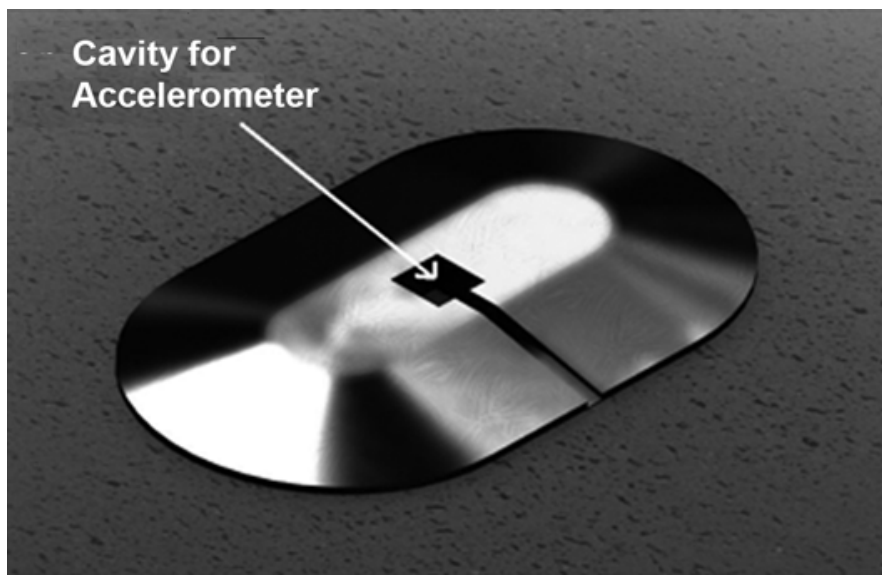

Figure 3.

SIT-BAR indenter used to load and vibrate wheelchair cushions.

the seat surface with a SIT-BAR indenter [8] (Figure 3) attached to the MTS actuator.

The reaction force below the cushion was measured with a 4550 Bertec force plate (Bertec Corporation; Columbus, Ohio) that was rigidly attached to the MTS base. Acceleration of the SIT-BAR was measured with a three-dimensional (3-D) accelerometer (CXL10LP3, \pm 10 g, 0-100 Hz, Moog Crossbow; Milpitas, California). Force and acceleration measurements were acquired at $200 \mathrm{~Hz}$ with an analog-to-digital acquisition card (DAQCardTM-6024E, National Instruments Corporation; Austin, Texas) and LabView Signal Express software (National Instruments Corporation). An algorithm was developed in MATLAB (The MathWorks, Inc; Natick, Massachusetts) to estimate the dynamic stiffness transfer function (Equation 4) from the acquired signals in the frequency domain and to compute the $K$ and $C$ dynamic parameters from the modulus of the dynamic stiffness: $\vec{S}=\sqrt{K^{2}+(C \omega)^{2}}$. Nonlinear least-squares curvefitting methods were used with an optimization algorithm (parameters were obtained with the MATLAB Curve Fit Toolbox).

Figure 4 shows the experimental setup, and the diagram on the bottom of Figure 1 conveys the mathematical representation of the system. Measurement of dynamic stiffness was performed three times per cushion at each preload.

\section{Measurement of Seated Transmissibility with Human Subjects}

Measurements of seated transmissibility were obtained for each seat cushion during field tests with 14 nondisabled

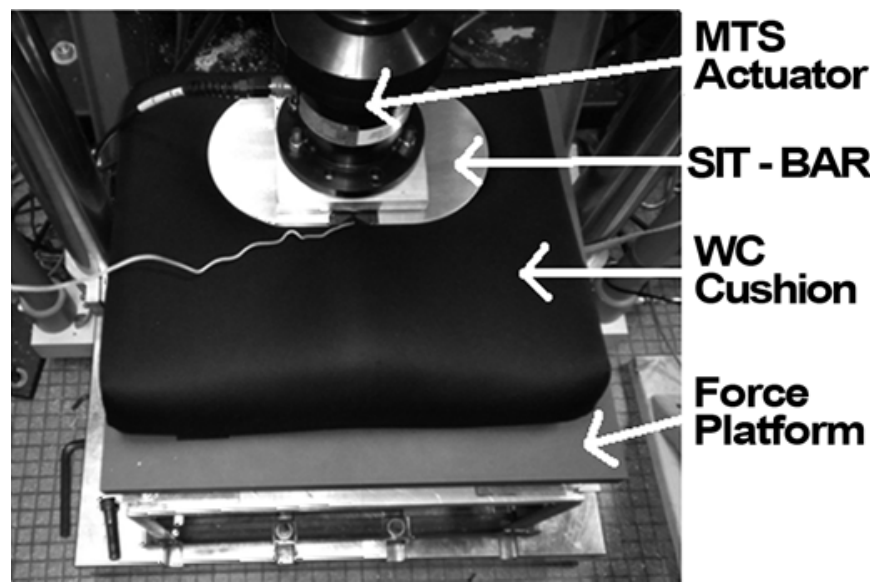

Figure 4.

Experimental configuration to measure dynamic stiffness of wheelchair (WC) cushions. MTS = material testing system.

human subjects. Informed consent and demographic information (sex, age, height, and weight) were gathered before each participant performed the field test (mean \pm standard deviation weight: $73.15 \pm 12.73 \mathrm{~kg}$ and height: $1.71 \pm$ $0.11 \mathrm{~m})$. Each person was asked to propel the same rigidframe WC (Quickie GP, Sunrise Medical; Stourbridge, United Kingdom) over a WC road course (WRC) to simulate activities of daily living while seated on each of the seven cushions. Each seat cushion was adjusted for each participant as indicated by the manufacturer. Measurements of accelerations at the WC-cushion interface and at the cushion-human interface were recorded using two 3-D accelerometers (Moog Crossbow) both located at the midline of the body under the ischial tuberosities. One accelerometer was placed under the cushion and attached to the WC frame using a 5/16 in.-thick aluminum seat pan (Figure 5). The second accelerometer was mounted in a SIT-BAR indenter and placed above the cushion for the subject to sit on (Figure 5). The SIT-BAR and seat-pan instrumentation were positioned and aligned as defined in ISO 2631-1 and ISO 10326-1 [14,24]. Data acquisition was performed using the same equipment and at the same frequency as described in the previous MTS section.

The WRC was created to replicate obstacles that WC users encounter in activities of daily living [17-18]. Obstacles included in the WRC were two $5 \mathrm{~cm}$ curb descents, a dimple strip mat, three sine-wave bumps (2.5, 5.0 , and $7.5 \mathrm{~cm}$, respectively), a simulated door threshold, industrial carpet, and a rumble bump mat. The WRC and the obstacles are shown in Figure 6. 


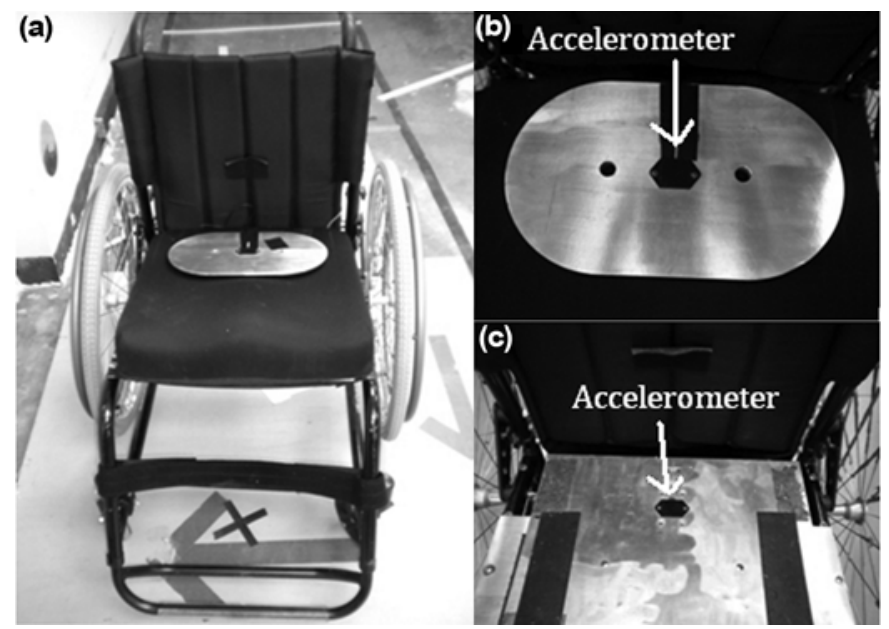

\section{Figure 5.}

(a) Manual wheelchair (WC) with Comfort Mate Foam cushion and SIT-BAR. (b) SIT-BAR with accelerometer attached. (c) Aluminum pan attached to WC frame with fixed accelerometer.

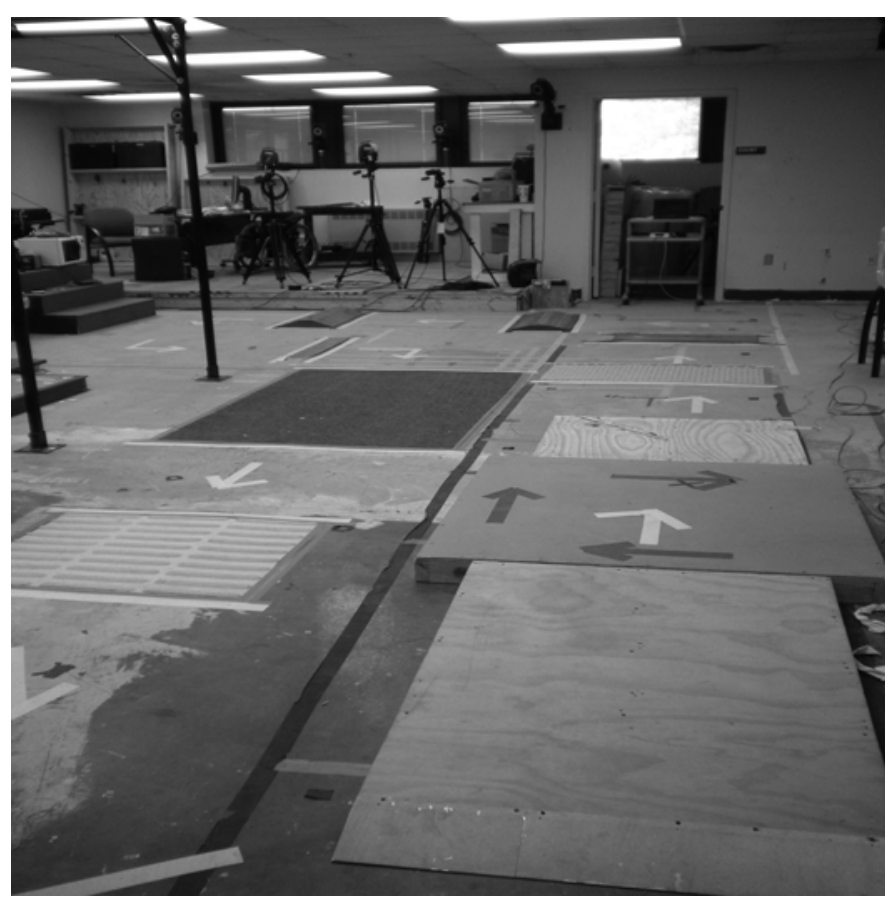

Figure 6.

Wheelchair road course.

Individuals propelled the WC in their most comfortable erect posture and at their self-selected velocity. The trial was repeated three times by every subject for each of the seven randomly presented cushions. The participants were allowed to rest or get out of the WC between trials.
Prior to data collection, each subject was trained in the WRC at least once to familiarize them with the obstacles.

Figure 1 shows the WC-seat-human system for this experiment. Seated transmissibility was calculated by the given equation:

$$
T(\omega)=\frac{\ddot{x}_{o}(\omega)}{\ddot{x}_{i}(\omega)},
$$

where $T(\omega)$ is the seated transmissibility, $\ddot{x}_{o}(\omega)$ is the output acceleration measured under the cushion, and $\ddot{x}_{i}(\omega)$ is the input acceleration measured above the cushion.

An algorithm written in MATLAB was developed to estimate the averaged transfer function (i.e., seated transmissibility) from the input and output acceleration signals for all the subjects and for each type of cushion at each sensor site (WC frame and seat surface).

\section{Mathematical Models of Seat Transmissibility}

Due to the dynamic interplay between the human body and the cushion, cushion vibration transmissibility from the MTS data must be calculated taking into account the response of the human body seated on it [8]. Wei and Griffin have developed different mathematical models for the human body that can be used to represent a person seated on a dynamic seating system (when vibrations occur) [23]. To predict seat vibration transmissibility without exposing human subjects to vibration, we used two mathematical models of the apparent mass of the human body (i.e., one-degree-of-freedom [ODOF] and two-degree-of-freedom [TDOF] models) in conjunction with the mechanical model of the seating system characterized previously and illustrated in the bottom of Figure 1. This methodology has already been shown to be appropriate for investigating seat dynamic performance from separate measurements of seat dynamic stiffness and the apparent mass of the human body [22]. The ODOF and TDOF models used to represent the cushionhuman body response to vertical vibrations are shown in Figure 7. Both models are represented by a support structure, $m$, and one or two mass-spring-damper systems (i.e., $K_{1}, C_{1}, m_{1}$ and/or $K_{2}, C_{2}, m_{2}$ ) that represent different parts of the human body supported by tissues. The model parameters $K_{1}, C_{1}, K_{2}, C_{2}, m, m_{1}$, and $m_{2}$ (obtained by Wei and Griffin from the analysis of measurements of the apparent masses of 60 persons [22-23]) are shown in Table 2. The $K$ and $C$ represent the seat dynamic parameters obtained from the characterization of each seat cushion in the first section of this study. 
(a)

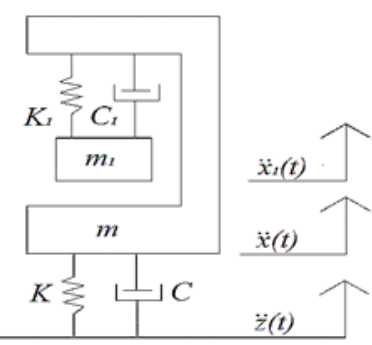

(b)

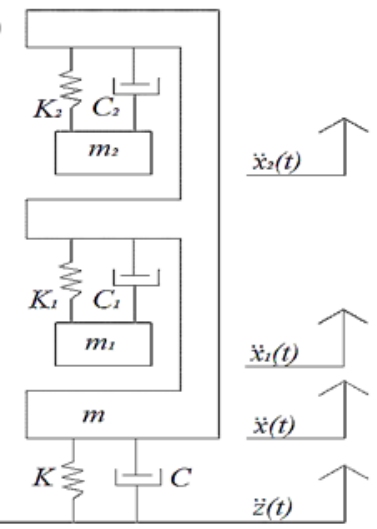

\section{Figure 7.}

(a) One-degree-of-freedom model of apparent mass of human body $\left(m_{1}\right)$. (b) Two-degree-of-freedom model of apparent mass of human body $\left(m_{1}\right.$ and $\left.m_{2}\right) . \ddot{x}(t), \ddot{x}_{1}(t)$, and $\ddot{x}_{2}(t)$ represent acceleration of each mass, respectively; and $\ddot{z}(t)$ acceleration and base of seat cushion.

The response of the ODOF model shown in Figure 7 is given by

$$
\begin{array}{r}
m_{1} \ddot{x}_{1}+K_{1}\left(x_{1}-x\right)+C_{1}\left(\dot{x}_{1}-\dot{x}\right)=0 \text { and } \\
m_{1} \ddot{x}_{1}+m \ddot{x}=K(z-x)+C(\dot{z}-\dot{x}) ;
\end{array}
$$

and the response of the TDOF model also shown in Figure $\mathbf{7}$ is given by

$$
\begin{gathered}
m_{1} \ddot{x}_{1}+K_{1}\left(x_{1}-x\right)+C_{1}\left(\dot{x}_{1}-\dot{x}\right)=0, \\
m_{2} \ddot{x}_{2}+K_{2}\left(x_{2}-x\right)+C_{2}\left(\dot{x}_{2}-\dot{x}\right)=0, \quad \text { and } \\
m \ddot{x}+m_{1} \ddot{x}_{1}+m_{2} \ddot{x}_{2}=K(z-x)+C(\dot{z}-\dot{x}) .
\end{gathered}
$$

The transmissibility of the seat cushion is given by the magnitude of the transfer function, $|H(\omega)|$, which can be derived from Equations $\mathbf{6}$ and $\mathbf{7}$ for the ODOF model [22] by

$$
\left|H_{\mathrm{ODOF}}(\omega)\right|=\left|\frac{\ddot{x}(\omega)}{\ddot{z}(\omega)}\right|=\left|\frac{(A+B i)}{(D+E i)}\right|=\sqrt{\frac{\left(A^{2}+B^{2}\right)}{\left(D^{2}+E^{2}\right)}} ;
$$

and from Equations $\mathbf{8}$ to $\mathbf{1 0}$ for the TDOF model by

$$
\left|H_{\mathrm{TDOF}}(\omega)\right|=\left|\frac{(F+G i)}{\{(H+L)+(M+N) i\}}\right|=\sqrt{\frac{\left(F^{2}+G^{2}\right)}{(H+L)^{2}+(M+N)^{2}}},
$$

where $A, B, D, E, F, G, H, L, M$, and $N$ are the polynomials of Equations 11 and 12 as defined in Figure 8 and simplified in the previous equations to improve readability.

For the ODOF model only, the mass was changed according to the averaged assumed sitting weight for all the subjects in the second section of this study. In other words, the term $\left(m+m_{1}\right)$ of the polynomial $D$ was made equal to 75 percent of the average total weight for all the subjects, as indicated in a previously cited study [23].

\section{Vibration Dose Value of Wheelchair Cushions}

Vibration dose value (VDV) is a vibration evaluation method defined by ISO 2631-1 [14] that is sensitive and useful for evaluating transient vibrations with occasional shocks. The VDV unit is meters per second to the power of 1.75 and is defined as

$$
\mathrm{VDV}=\left\{\int_{0}^{T}\left[a_{w}(t)\right]^{4} d t\right\}^{\frac{1}{4}},
$$

where $a_{w}(t)$ is the instantaneous frequency-weighted acceleration and $T$ is the duration of the measurement.

Vibration frequency content and axis have different effects on health than on comfort, perception, and motion sickness. To appropriately evaluate the effects of vertical vibrations on the health of seated humans, we applied a frequency-weighting filter as indicated by ISO 2631-1 [14] to the measured input and output accelerations before VDVs were estimated for both vibration measurements. The input and output accelerations were collected at the WC frame below the cushion and between the person and the cushion with the SIT-BAR during the WRC test. The transmissibility of each cushion was calculated with the VDV as defined in Equation 14:

$$
\mathrm{T}=\frac{\mathrm{VDV}_{\mathrm{o}}}{\mathrm{VDV}_{\mathrm{i}}}
$$

where $\mathrm{VDV}_{\mathrm{i}}$ is the VDV estimated with the input acceleration data and $\mathrm{VDV}_{\mathrm{o}}$ is the VDV estimated with the output acceleration data, both estimated over the entire WRC. 
Table 2.

Parameters of one-degree-of-freedom (ODOF) model and two-degree-of-freedom (TDOF) model of apparent mass of human body.

\begin{tabular}{lccccccc}
\hline Mathematical Model & $\boldsymbol{K}_{\mathbf{1}} \mathbf{( N / \mathbf { m } )}$ & $\left.\boldsymbol{C}_{\mathbf{1}} \mathbf{( N s} / \mathbf{m}\right)$ & $\boldsymbol{K}_{\mathbf{2}} \mathbf{( N / \mathbf { m } )}$ & $\boldsymbol{C}_{\mathbf{1}}(\mathbf{N s} / \mathbf{m})$ & $\boldsymbol{m} \mathbf{( k g})$ & $\boldsymbol{m}_{\mathbf{1}} \mathbf{( k g )}$ & $\boldsymbol{m}_{\mathbf{2}}(\mathbf{k g})$ \\
\hline ODOF & 44,130 & 1,485 & - & - & 7.8 & 43.4 & - \\
TDOF & 35,776 & 761 & 38,374 & 458 & 6.7 & 33.4 & 10.7 \\
\hline \hline
\end{tabular}

\section{Statistical Analysis}

After testing for normality, we performed two statistical analyses with repeated measures one-way analysis of variance (ANOVA) to evaluate whether differences existed (1) in the measured and estimated ODOF and TDOF transmissibility for all the seating systems and (2) in the estimated VDV transmissibility for all the seating systems. If significant differences were present, a Sidak post hoc analysis was performed for each ANOVA. Additionally, a correlation analysis was performed between predicted transmissibility obtained with the ODOF and TDOF models and the measured values of transmissibility with the WRC test.

\section{RESULTS}

\section{Dynamic Characterization of Wheelchair Cushions}

Figure 9 shows the measured modulus of the dynamic stiffness, $\vec{S}=\sqrt{K^{2}+(C \omega)^{2}}$, of the seven seating systems for all the preloads (300-800 N). All curves of the modulus of the dynamic stiffness over the range of loads (300-800 N) were fitted within the 95 percent goodness of fit to estimate stiffness and damping values. The estimated stiffness and the damping parameters for the seven different seating systems are shown in Table 3. All the cushions show increases in the stiffness and damping characteristics with increments in the preload. The Comfort Mate Foam (Invacare; Elyria, Ohio) and the Zoombang Protective Gear with Foam (Invacare) had the largest stiffness and damping values compared with the other cushions. The Jay J2 Deep Contour (Sunrise Medical) cushion had the lowest stiffness coefficients over the preload range, whereas the Meridian Wave (Varilite; Seattle, Washington) cushion showed the lowest damping coefficients. The former pair of seating systems also had the highest rate of increase in both the stiffness and damping parameters with increasing preloads. The Jay J2 Deep Contour and the Meridian Wave cushions had the lowest rates of increase of damping, and the Jay J2 Deep Contour and the ROHO LOW PROFILE (The ROHO Group; Belleville, Illinois) had the lowest rates of increase of stiffness.

\section{Measurement and Prediction of Cushion Transmissi- bility with Nondisabled Subjects and Mathematical Models}

Fourteen subjects participated in the WRC test to measure and estimate vibration transmissibility of seven

\begin{tabular}{|c|c|c|c|c|}
\hline $\begin{array}{l}A \\
=K K_{1}-\left(m_{1} K\right. \\
\left.+C C_{1}\right) \omega^{2}\end{array}$ & $\begin{array}{l}B \\
=\left(C_{1} K+C K_{1}\right) \omega \\
-m_{1} C \omega^{3}\end{array}$ & $\begin{array}{l}D \\
=(K \\
\left.-\left(m+m_{1}\right) \omega^{2}\right) K_{1} \\
+\left(m m_{1} \omega^{2}-K m_{1}\right. \\
\left.-C C_{1}\right) \omega^{2}\end{array}$ & $\begin{array}{l}E \\
=\left(K C_{1}+K_{1} C\right. \\
-\left(m_{1} C+m C_{1}\right. \\
\left.\left.+m_{1} C_{1}\right) \omega^{2}\right) \omega\end{array}$ & $F=K P_{1}-C P_{2} \omega$ \\
\hline$G=K P_{2}-C P_{1} \omega$ & $\begin{array}{l}H \\
=P_{1} P_{5}-P_{2} C \omega \\
-m_{1} K_{1} P_{3} \omega^{2}\end{array}$ & $\begin{array}{l}L \\
=m_{1} C_{1} C_{2} \omega^{4} \\
-\left(m_{2} K_{2} P_{4} \omega^{2}\right. \\
\left.-m_{2} C_{1} C_{2} \omega^{4}\right)\end{array}$ & $\begin{array}{l}N \\
=\left(m_{2} C_{2} P_{4} \omega^{3}\right. \\
\left.+m_{2} K_{2} C_{1} \omega^{3}\right)\end{array}$ & $\begin{array}{l}P_{1} \\
=m_{1} m_{2} \omega^{4}+K_{1} K_{2} \\
-\left(m_{1} K_{2}+m_{2} K_{1}\right. \\
\left.+C_{1} C_{2}\right) \omega^{2}\end{array}$ \\
\hline $\begin{array}{l}P_{2} \\
=\left(C_{1} K_{2}\right. \\
\left.+C_{2} K_{1}\right) \omega \\
-\left(m_{1} C_{2}\right. \\
\left.+m_{2} C_{1}\right) \omega^{3}\end{array}$ & $P_{3}=K_{2}-m_{2} \omega^{2}$ & $P_{4}=K_{1}-m_{1} \omega^{2}$ & \multicolumn{2}{|c|}{$P_{5}=K-m \omega^{2}$} \\
\hline
\end{tabular}

Figure 8.

Definitions of polynomials found in Equations $\mathbf{1 1}$ and $\mathbf{1 2 .}$ 


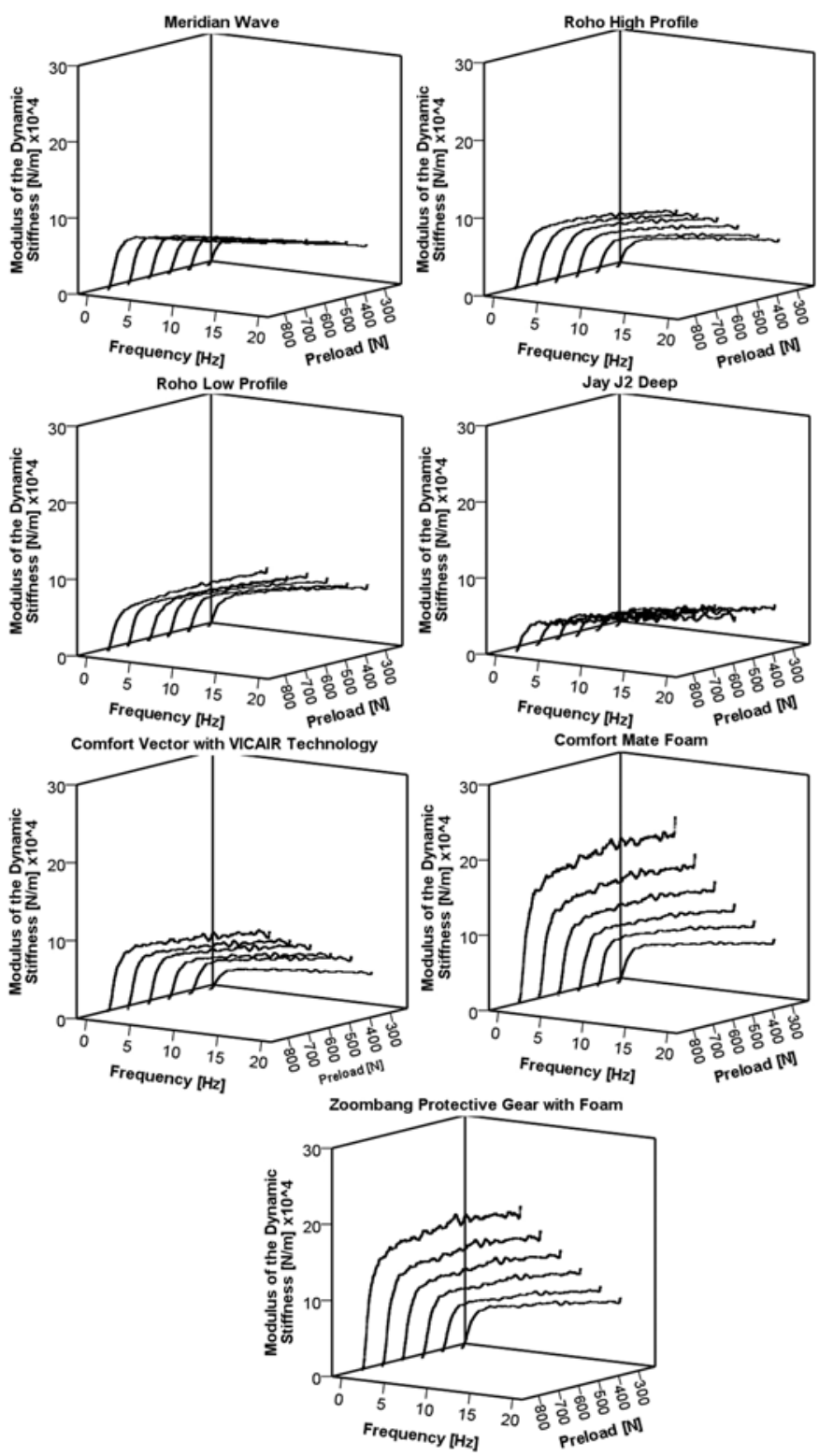

Figure 9.

Material testing system-measured modulus of dynamic stiffness for all preload forces of seven seating systems.

seating systems. Figure 10 shows the averaged measured seat transmissibility obtained in the WRC test of the seven seating systems compared with the ODOF and TDOF models of the seat transmissibility calculated with Equations 11 and 12. As can be seen from these figures, all seating systems amplified vibrations in a frequency range harmful to humans when measured or predicted with mathematical models. However, neither ODOF nor TDOF models accurately predicted measured seat trans- missibility during the WRC test. Both models overestimated seat transmissibility during WC propulsion at low frequency ranges (below $8 \mathrm{~Hz}$ ). In addition, the models predicted lower seat transmissibilities at frequencies between 8 and $12 \mathrm{~Hz}$, which underestimated measured seat transmissibilities during the WRC test.

An average PSD of the input vibration exposure of the subjects in the WRC test is shown in Figure 10 (bottom right corner). This figure shows that the spectral content is not the same throughout the frequency range from $0-20 \mathrm{~Hz}$ and differs from the flat spectrum the cushions are subjected to with the MTS. The PSD of the vibration exposure during the WRC test is higher at frequencies from $8-20 \mathrm{~Hz}$ than frequencies below $8 \mathrm{~Hz}$.

A summary of the maximum measured and predicted transmissibilities and corresponding frequencies for the seven seating systems are listed in Table 4. Neither mathematical model accurately predicted the maximum measured seat transmissibility. The ODOF model predicted that the Jay J2 Deep Contour and Meridian Wave have the highest maximum transmissibility and that the Comfort Mate Foam and Zoombang Protective Gear with Foam have the lowest maximum transmissibility. The TDOF model predicted different results. With this model, the Meridian Wave was identified as the cushion with the highest maximum transmissibility, whereas the ROHO LOW PROFILE, the Comfort Mate Foam, and the Zoombang Protective Gear with Foam were identified as the cushions with the lowest maximum transmissibility. These results differ from measured results, which identified the Comfort Mate Foam and the ROHO HIGH PROFILE as the cushions with the highest maximum transmissibility and the Jay J2 Deep Contour and the Vector with Vicair Technology as the cushions with the lowest maximum transmissibility.

Maximum seat transmissibility and frequency estimations from the ODOF and TDOF models were significantly higher than those measured in the WRC test. After logtransformation of data was performed for normality, we performed repeated-measures ANOVA with Sidak adjustment for multiple comparisons. We found significant effects of the methods used on both the transmissibility and the corresponding frequency $(F=24.127, d f=2, \rho<0.001$; and $F=13.352, d f=1.084, \rho=0.009$, respectively). Sidak post hoc analysis results showed a significant effect on transmissibility between measured data and ODOF model predictions ( $p=0.02, \alpha=0.05$ ) and between measured data and TDOF model predictions $(p=0.001, \alpha=0.05)$ and a 
Table 3.

Stiffness and damping parameters, $K$ (in N/m) and $C$ (in Ns/m), of seven wheelchair cushions over range of preloads (300-800 N).

\begin{tabular}{|c|c|c|c|c|c|c|c|c|c|c|c|c|c|c|}
\hline \multirow[t]{2}{*}{ Load (N) } & \multicolumn{2}{|c|}{$\begin{array}{c}\text { Vector with } \\
\text { Vicair }\end{array}$} & \multicolumn{2}{|c|}{$\begin{array}{l}\text { Meridian } \\
\text { Wave }\end{array}$} & \multicolumn{2}{|c|}{$\begin{array}{l}\text { ROHO HIGH } \\
\text { PROFILE }\end{array}$} & \multicolumn{2}{|c|}{$\begin{array}{c}\text { Jay J2 Deep } \\
\text { Contour }\end{array}$} & \multicolumn{2}{|c|}{$\begin{array}{l}\text { ROHO LOW } \\
\text { PROFILE }\end{array}$} & \multicolumn{2}{|c|}{$\begin{array}{c}\text { Zoombang } \\
\text { Protective Gear } \\
\text { with Foam }\end{array}$} & \multicolumn{2}{|c|}{$\begin{array}{c}\text { Comfort Mate } \\
\text { Foam }\end{array}$} \\
\hline & $K$ & $C$ & $K$ & $C$ & $K$ & $C$ & $K$ & $C$ & $K$ & $C$ & $K$ & $C$ & $K$ & $C$ \\
\hline$\overline{300}$ & 32,080 & 318 & 40,230 & 301 & 43,180 & 389 & 26,730 & 365 & 50,520 & 544 & 60,350 & 573 & 56,780 & 487 \\
\hline 400 & 50,340 & 478 & 50,500 & 322 & 51,740 & 475 & 27,940 & 406 & 56,730 & 602 & 74,160 & 727 & 76,140 & 696 \\
\hline 500 & 59,360 & 542 & 57,550 & 337 & 64,840 & 596 & 28,710 & 377 & 62,140 & 708 & 94,900 & 938 & 93,070 & 908 \\
\hline 600 & 71,580 & 665 & 64,760 & 372 & 77,390 & 688 & 36,890 & 508 & 64,460 & 835 & 116,900 & 1,132 & 115,500 & 1,149 \\
\hline 700 & 80,870 & 748 & 69,730 & 392 & 86,470 & 760 & 36,090 & 522 & 65,900 & 855 & 141,800 & 1,311 & 143,200 & 1,408 \\
\hline 800 & 95,040 & 840 & 76,010 & 397 & 94,220 & 834 & 39,970 & 571 & 68,600 & 1,015 & 174,900 & 1,507 & 183,200 & 1,689 \\
\hline $\begin{array}{l}\text { Rate of } \\
\text { Increase/100 N }\end{array}$ & 11,960 & 101 & 6,966 & 21 & 10,627 & 91 & 2,823 & 43 & 3,435 & 93 & 22,791 & 189 & 24,449 & 240 \\
\hline
\end{tabular}

significant effect on frequency between measured data and TDOF model predictions ( $p=0.03, \alpha=0.05$ ) and ODOF and TDOF model predictions ( $p=0.02, \alpha=0.05$ ).

\section{Vibration Dose Values of Wheelchair Cushions}

Figure 11 shows the VDV transmissibility measured in the WRC test. After log-transformation of data was performed for normality, we performed repeated-measures ANOVA with Sidak adjustment for multiple comparisons. We found significant effects of cushion on the VDV transmissibility $(F=7.219, d f=2.985, \rho=0.001)$. The Meridian Wave, Vector with Vicair Technology, and ROHO HIGH PROFILE cushions had the lowest transmissibility, whereas the Jay J2 Deep Contour, Comfort Mate Foam, and Zoombang Protective Gear with Foam had the highest transmissibility.

Figure 11 shows a box-plot of the VDV transmissibility and statistical groupings. Sidak post hoc analysis results revealed significant differences between (1) Jay J2 Deep Contour and Vector with Vicair technology ( $\rho=$ 0.003, $\alpha=0.05$ ), (2) Meridian Wave and Jay J2 Deep Contour ( $\rho<0.001, \alpha=0.05)$, (3) Meridian Wave and Zoombang Protective Gear with Foam $(\rho=0.014, \alpha=$ 0.05), (4) Meridian Wave and Comfort Mate Foam ( $\rho=$ 0.012, $\alpha=0.05$ ), and (5) ROHO HIGH PROFILE and Comfort Mate Foam $(\rho=0.03, \alpha=0.05)$.

\section{DISCUSSION}

Dynamic properties of seven different WC cushions were obtained with two laboratory test methods. Different stiffness and damping parameters (Table 3) among the WC cushions were found and are attributable to their construction materials. The Comfort Mate Foam and the
Zoombang Protective Gear with Foam cushions had the highest values of dynamic stiffness in contrast with the other seating systems, which have more complex constructions of air-foam, air-gel, or air. For instance, the air suspension properties of the ROHO HIGH PROFILE and ROHO LOW PROFILE cushions resulted in low stiffness values in contrast with the Comfort Mate Foam cushion. In the same way, the Meridian Wave cushion showed similar stiffness but lower damping to the air group cushions. This may be due to the low stiffness of its foam base component (lower than the foam cushion), which contrasted with the higher stiffness of the compartments of the ROHO cushions during compression. On the other hand, the Jay J2 Deep Contour cushion showed low values of stiffness and damping. The viscous gel contained in this cushion behaves like a solid during highimpact vibrations and is not good for suppressing vibrations [20]. It was observed that the gel slowly moved out of the area under the indenter, which may have decreased its dynamic stiffness. As preload increased, this effect was more noticeable and may have been a consequence of using the SIT-BAR as the indenter, although it is the industry standard for measuring vibration exposure under the seated individual. This effect occurs with WC users as well.

Figure 10 and Table 4 show that the ODOF and TDOF models failed to predict the seat transmissibility obtained in the WRC test. A possible reason for this could be that the ODOF and TDOF mathematical models were developed to fit seat transmissibility data obtained by directly vibrating human subjects with a vibrator table excited by random vibration with a flat acceleration PSD over the range 1-30 $\mathrm{Hz}$ [22], whereas the frequency content of the vibration produced by the WRC was variable. In addition, the WRC may not excite all modes of the 

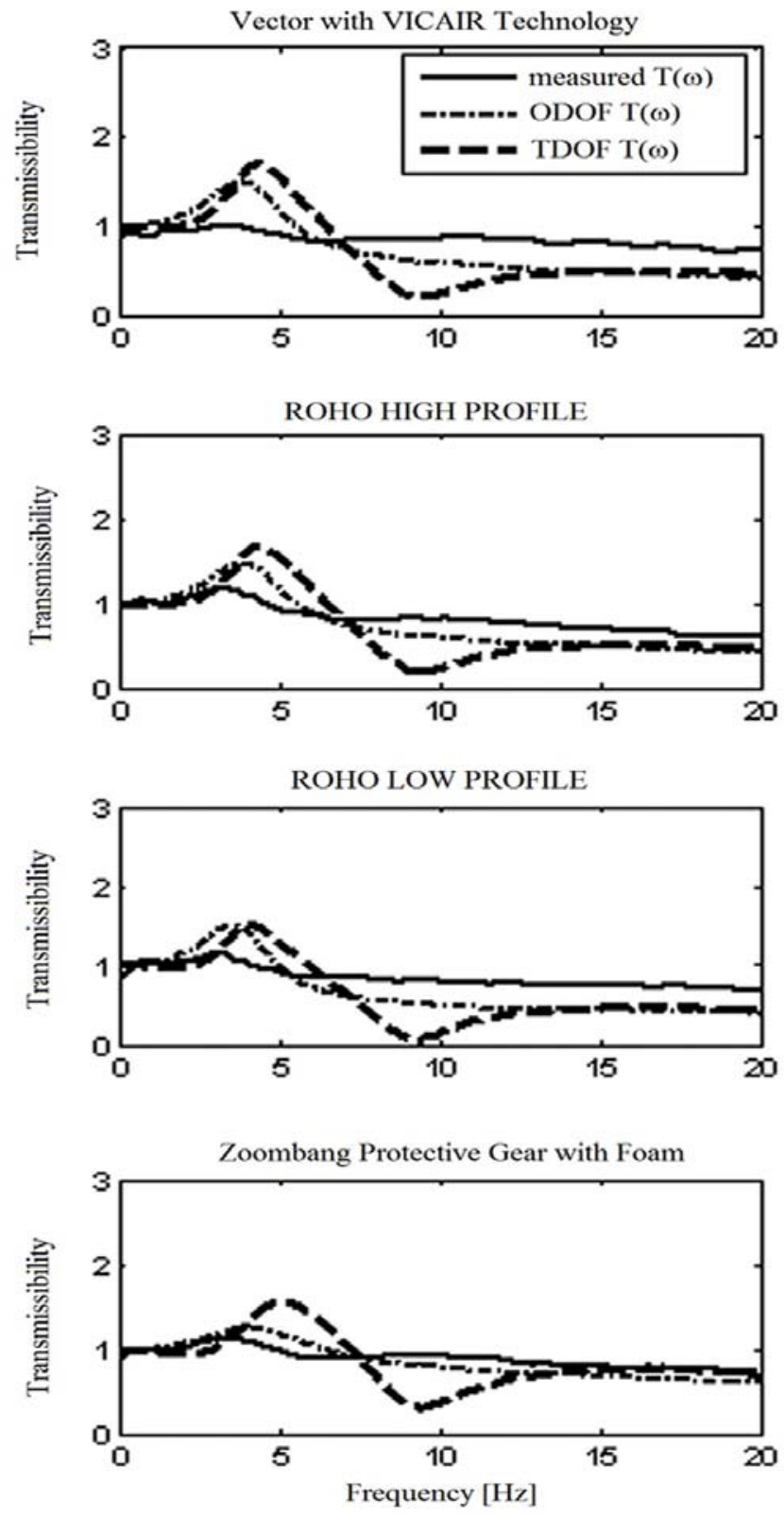
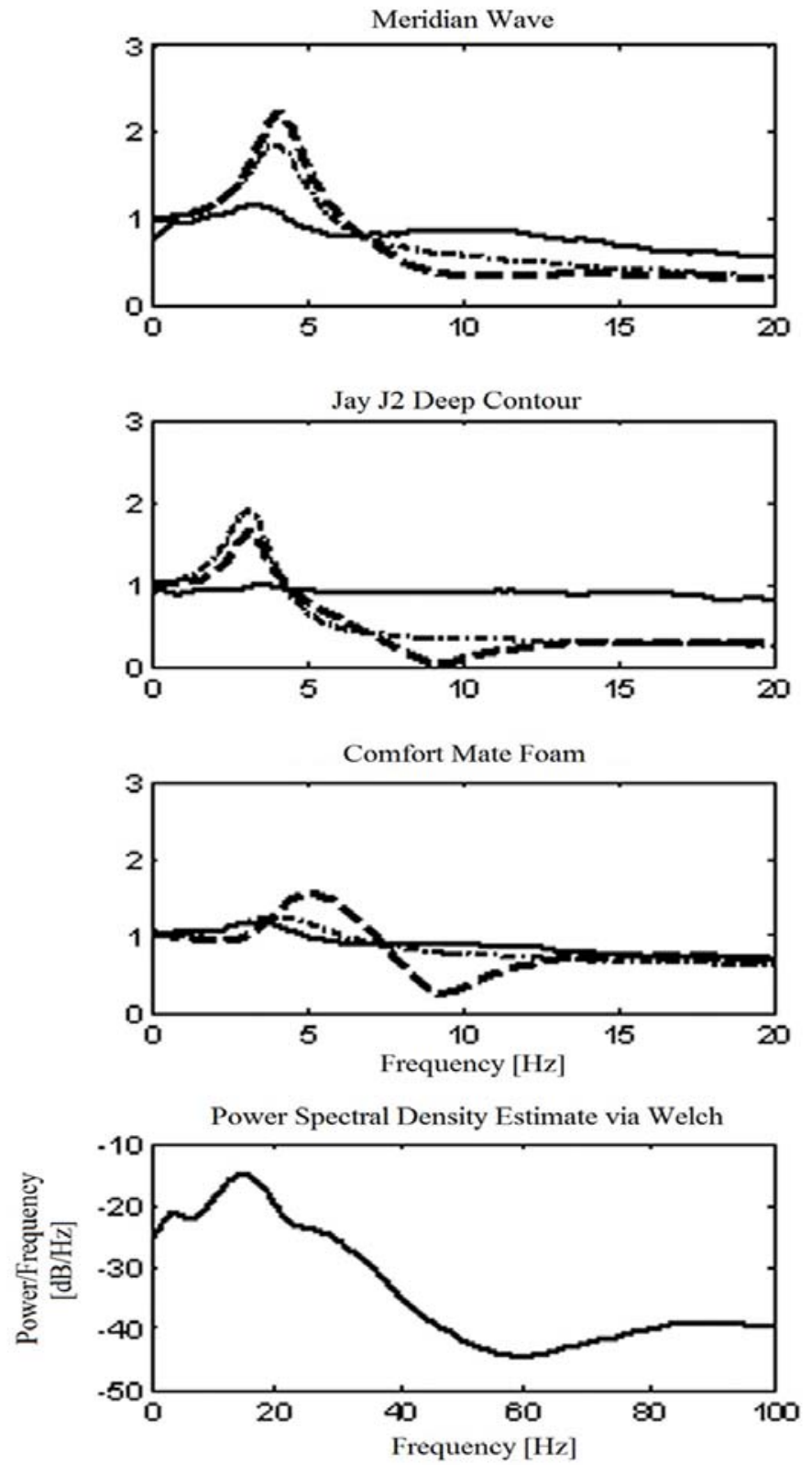

Figure 10.

Measured and predicted seat transmissibility for seven seating systems. Bottom-right corner: power spectral density of averaged input acceleration of wheelchair road course.

cushion, and those that are excited may not be excited with equal power. A PSD of the input vibration exposure of the subjects in the WRC test is shown in Figure 10 (bottom right corner). This figure shows that the spectral content is neither flat nor the same throughout the range from $0-20 \mathrm{~Hz}$. In addition to the PSD of the input vibration, other factors could affect seat transmissibility measures. For instance, subjects' body position (i.e., leg and back position, contact with backrest, contact with footrest, and arm support) has been show to affect seat transmissibility measurements [8]. Asking individuals to propel the WC may have had an important effect on their body position and load distribution on the seat, thereby affecting seat transmissibility measurements. For example, leaning forward off of the backrest has been shown to decrease the resonance frequency [8]. With vibrations 
Table 4.

Maximum transmissibility and corresponding frequency values obtained in WRC test and ODOF and TDOF models of seating systems.

\begin{tabular}{|c|c|c|c|c|c|c|}
\hline \multirow[b]{2}{*}{ Cushion } & \multicolumn{2}{|c|}{ WRC } & \multicolumn{2}{|c|}{ ODOF } & \multicolumn{2}{|c|}{ TDOF } \\
\hline & $\begin{array}{c}\text { Frequency } \\
\text { (Hz) }\end{array}$ & $\mathbf{T}$ & $\begin{array}{c}\text { Frequency } \\
\text { (Hz) }\end{array}$ & $\mathbf{T}$ & $\begin{array}{c}\text { Frequency } \\
\text { (Hz) }\end{array}$ & $\mathbf{T}$ \\
\hline$\overline{\mathrm{ROHO} \text { LOW PROFILE }}$ & 3.12 & 1.16 & 3.56 & 1.51 & 4.10 & 1.52 \\
\hline Jay J2 Deep Contour & 3.48 & 0.99 & 3.13 & 1.90 & 3.17 & 1.64 \\
\hline ROHO HIGH PROFILE & 3.37 & 1.18 & 3.88 & 1.48 & 4.40 & 1.67 \\
\hline Meridian Wave & 3.34 & 1.16 & 3.99 & 1.85 & 4.10 & 2.22 \\
\hline Vector with Vicair Technology & 3.27 & 1.01 & 3.87 & 1.50 & 4.35 & 1.69 \\
\hline Zoombang Protective Gear with Foam & 3.36 & 1.13 & 4.21 & 1.27 & 5.15 & 1.56 \\
\hline Comfort Mate Foam & 3.16 & 1.18 & 4.13 & 1.26 & 5.13 & 1.55 \\
\hline$\overline{\text { Mean } \pm \text { Standard Deviation }}$ & $3.30 \pm 0.13$ & $1.12 \pm 0.08$ & $3.82 \pm 0.37$ & $1.54 \pm 0.25$ & $4.34 \pm 0.68$ & $1.69 \pm 0.24$ \\
\hline
\end{tabular}

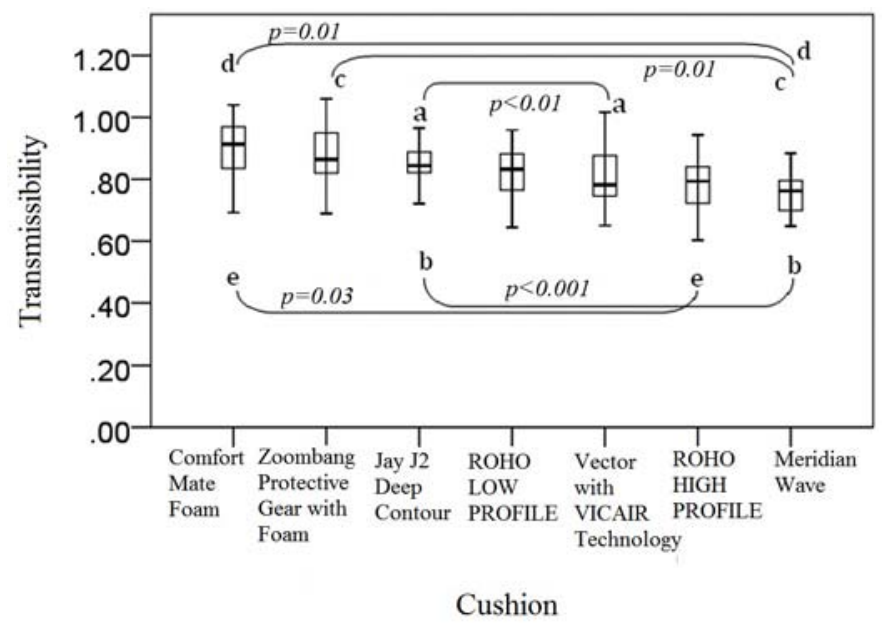

Figure 11.

Distribution of vibration dose value transmissibilities measured in wheelchair road course for seven seating systems. a, b, c, d, and e identify cushions with significant differences.

at a frequency just above resonance, subjects' leaning forward off of the backrest also caused significant decreases in seat transmissibility [8]. In addition, during the WRC test, the individuals had support for their feet, had to lean forward to ride the WC over obstacles (especially for the ramp and the sine-wave bumps), and had constant hand contact with the hand rim of the rear wheels. Furthermore, changes in trunk position during WC propulsion may also have a significant effect on the center of mass of the body (i.e., the total load applied on the seat). Because seat transmissibility is a function of both the apparent mass and the dynamic stiffness of the cushion, changes in the load applied on the seat cushion (as either a preload or the subject's apparent mass) may have significantly affected seat transmissibility measurements. An example of the effect of changes in preload on the dynamic stiffness of the cushion is clearly illustrated in Figure 9. Some studies have also found very little effect on vertical seat-to-head transmissibility measurements when vibrating the same subject without change of posture, whereas varying the body posture to a more erect position significantly increased the transmissibility at all frequencies above $3 \mathrm{~Hz}$. Table 4 shows significant decreases in maximum seat transmissibility and corresponding frequency during the WRC, which were probably caused by changes in body position. Furthermore, increasing user contact with the seat surface while the user "pulls-up" against the hand rim has been shown to decrease accelerations measured at the head [25].

Although pull-ups were not allowed in this study, subjects' use of the hand rim while traversing obstacles in the WRC may have had an effect on the amount of user contact with the seat surface, thereby changing the acceleration experienced at the user-seat interface. Additionally, individuals in the WRC propelled the WC at self-selected speeds that were not constant among all the participants. Variations in speed cause variations in vibration magnitude and frequency, which can affect the cushion-human system, thereby affecting seat transmissibility and resonance frequency measurements [8]. Griffin and Erdreich point out that increases in vibration magnitude produce decreases in seat transmissibility and resonance frequency [8]. The WRC includes obstacles that produce highmagnitude vibration impacts (e.g., the double curb descent shown in Figure 6), which may also contribute to reductions in maximum transmissibility and corresponding frequency. To measure seat vibration, we collected acceleration measurements at the human-cushion interface 
using the SIT-BAR to attach the accelerometers instead of the interface device developed by the Society of Automotive Engineers (SAE), the SAE pad [8], which was used for the development of the mathematical models. This may have had an effect on the cushion's surface deformation (especially for the gel cushion as it shifts the body down), the participant's position on the cushion, and the body contact area, thereby affecting transmissibility measurements. Unlike the SIT-BAR, the SAE pad is a thin "semi-rigid" ring that adjusts to the surface of the seat when loaded [8]. We preferred the SIT-BAR because its contour is similar to the human buttocks [8] and its rigid material and thickness allow it to be easily attached to the MTS. Finally, although the WC was not fit to participants as it would be to a client, the use of a single WC helped eliminate the effects of different WC types on the vibration transmissibility.

Although a drawback of this study was that the transmissibility measured with the MTS and on the WRC did not correspond well, we demonstrated the challenge of trying to accurately model WC propulsion with simple mathematical models. Future work will explore how to improve these models to better represent vibration transmission during WC propulsion and avoid use of disabled subjects for testing dynamic stiffness and measuring seat transmissibility. As a first step, we plan to develop a dynamic road simulator so subjects can be exposed to prescribed vibrations while acceleration measurements are collected above the cushion and at the head.

Significant differences were found between the VDV transmissibility measured on the WRC and the transmissibility from the models. These results may have important implications for WC cushion recommendations and selections for active WC users who are exposed to WBV on a daily basis. Figure 11 shows different transmissibility values among cushions estimated via the VDV method. Cushions with an air component had lower VDV than foam or gel cushions. For instance, the ROHO HIGH PROFILE and the Meridian Wave cushions had the lowest transmissibility values, while the Comfort Mate Foam and Jay J2 Deep Contour had the highest. No significant differences were found between the Comfort Mate Foam and the Zoombang Protective Gear with Foam ( $p=0.439, \alpha=0.05)$, suggesting that the Zoombang Protective Gear with Foam was not successful in reducing vibration exposure. The WRC results are consistent with prior results reported by DiGiovine et al. [20] and suggest that air-based cushions, or those with an air component, may be better at reducing vibration transmissibility than foam- or gel-based cushions.

It is important to note that the WRC test and VDV transmissibility methods produced different results. While VDV is an evaluation method whose output is a single value over the entire range of frequencies that does not provide information at specific frequencies, the WRC test is a means to simulate and measure vibrations over a range of frequencies and does not provide an assessment score. Moreover, the VDV method applies a weighted frequency filter to the acceleration data for VDV transmissibility estimation. The filter weights those accelerations at frequencies more dangerous for health.

Future research to characterize WC cushions should investigate the use of other indenters. For example, the rigid cushion loading indenter described by ISO 16840-2 may be a better representation of human anatomy than the SIT-BAR and may provide more accurate measurements of seat dynamic stiffness. Dynamic stiffness values are input parameters for mathematical models of humancushion systems. In addition to measurements of the dynamic response of WC cushions to vibration (such as those provided in this study), future studies should include measurements of the cushion's ability to absorb impacts related to curb descents and other obstacles as defined by ISO 16840-2 [26]. For instance, Sprigle et al. found different results than those found in this study regarding the ability of foam cushions to absorb vibrations and impact [27]. Yet Sprigle et al. used initial impact accelerations and rebounds as metrics of vibration and impact absorption rather than seat transmissibility. Their results showed that a 3 in.-flat foam cushion decreased initial impact acceleration during impact loading more than the other cushions in the test, suggesting greater dampening characteristics. Still the authors point out that more research is needed to relate results to clinical outcomes.

A final limitation of this study was the assumption that WC users can be represented by nondisabled subjects. It has been shown that disabled subjects have different biomechanics and body characteristics than nondisabled subjects, thereby affecting measurements of seat transmissibility. Future investigations should consider these factors when examining dynamic seat response to vibrations.

Future research should attempt to collect vibration exposure in the community for long durations. Combined with accurate measures of cushion transmissibility and comfort levels, this exposure data would be helpful in 
determining the health risks posed to the WC user and which cushions would reduce that risk. As a final recommendation, future work should also focus on objective measurements of ride comfort and back pain levels to explore their relationship with vibration exposure.

\section{CONCLUSIONS}

Selection of a WC cushion is critical to the health and safety of the WC user, especially if he or she has lost sensation. The most important variables driving the selection of a cushion are the pressure-relieving properties, weight, thermal properties, and ability to be cleaned. In this study, we demonstrated that transmissibility is another important characteristic to consider, as most cushions amplify vibrations (Table 4; $\mathrm{T}>1.0$ ). Air-based cushions outperformed the gel- and foam-based cushions and should be considered when selecting a cushion to help reduce vibration exposure or as a precaution against spinal pain.

Our transmissibility measurements calculated using the MTS and on the WRC did not correlate well, indicating that future work needs to focus on developing mathematical models of the body that better predict the dynamic response that occurs when propelling a WC. The development of such mathematical models will have important repercussions on WC cushion design and the prevention of health consequences when subjects test cushion dynamic stiffness.

\section{ACKNOWLEDGMENTS}

\author{
Author Contributions: \\ Study concept and design: J. L. Pearlman, R. A. Cooper, \\ M. L. Boninger. \\ Acquisition of data: Y. Garcia-Mendez. \\ Analysis and interpretation of data: Y. Garcia-Mendez. \\ Drafting of manuscript: Y. Garcia-Mendez. \\ Critical revision of manuscript for important intellectual content: \\ R. A. Cooper, M. L. Boninger. \\ Principal investigator: J. L. Pearlman. \\ Direct oversight of data collection and analysis: J. L. Pearlman. \\ Obtained funding: J. L. Pearlman.
}

Financial Disclosures: The authors have declared that no competing interests exist.

Funding/Support: This material is the result of work supported by VA Veterans Integrated Service Network 4 Competitive Pilot Project Fund (grant 02778), Career Development Award (grant B6673M), Wheelchair and Associated Rehabilitation Engineering (WaRE) VA
Center of Excellence (grant B6789C), and the Mexican National Council of Science and Technology Scholarship (register 212007).

Additional Contributions: The authors would like to thank the Human Engineering Research Laboratories staff and clinical coordinators. Institutional Review: The protocol was approved by the VAPHS Institutional Review Board (02778). Informed consent was provided by each participant.

Participant Follow-Up: The authors do not plan to inform participants of the publication of this study.

Disclaimer: The contents of this manuscript do not represent the views of the VA or the U.S. Government.

\section{REFERENCES}

1. Strine TW, Hootman JM. US national prevalence and correlates of low back and neck pain among adults. Arthritis Rheum. 2007;57(4):656-65. [PMID: 17471542]

http://dx.doi.org/10.1002/art.22684

2. Boninger ML, Cooper RA, Fitzgerald SG, Lin J, Cooper R, Dicianno B, Liu B. Investigating neck pain in wheelchair users. Am J Phys Med Rehabil. 2003;82(3):197-202.

[PMID: 12595772]

http://dx.doi.org/10.1097/01.PHM.0000054217.17816.DD

3. Siddall PJ, McClelland JM, Rutkowski SB, Cousins MJ. A longitudinal study of the prevalence and characteristics of pain in the first 5 years following spinal cord injury. Pain. 2003;103(3):249-57. [PMID: 12791431] http://dx.doi.org/10.1016/S0304-3959(02)00452-9

4. Hill TE, Desmoulin GT, Hunter CJ. Is vibration truly an injurious stimulus in the human spine? J Biomech. 2009; 42(16):2631-35. [PMID: 19880126] http://dx.doi.org/10.1016/j.jbiomech.2009.10.001

5. Seidel H, Heide R. Long-term effects of whole-body vibration: A critical survey of the literature. Int Arch Occup Environ Health. 1986;58(1):1-26. [PMID: 3522434] http://dx.doi.org/10.1007/BF00378536

6. Lings S, Leboeuf-Yde C. Whole-body vibration and low back pain: A systematic, critical review of the epidemiological literature 1992-1999. Int Arch Occup Environ Health. 2000;73(5):290-97. [PMID: 10963411] http://dx.doi.org/10.1007/s004200000118

7. Bakker EW, Verhagen AP, Van Trijffel E, Lucas C, Koes BW. Spinal mechanical load as a risk factor for low back pain: A systematic review of prospective cohort studies. Spine (Phila Pa 1976). 2009;34(8):E281-93.

[PMID: 19365237] http://dx.doi.org/10.1097/BRS.0b013e318195b257

8. Griffin M, Erdreich J. Handbook of human vibration. San Diego (CA): Academic Press Inc; 1990.

9. DiGiovine CP, Cooper RA, Fitzgerald SG, Boninger ML, Wolf EJ, Guo S. Whole-body vibration during manual wheelchair propulsion with selected seat cushions and back 
supports. IEEE Trans Neural Syst Rehabil Eng. 2003; 11(3):311-22. [PMID: 145187896]

http://dx.doi.org/10.1109/TNSRE.2003.816872

10. Totosy de Zepetnek JO, Giangregorio LM, Craven BC. Whole-body vibration as potential intervention for people with low bone mineral density and osteoporosis: A review. J Rehabil Res Dev. 2009;46(4):529-42. [PMID: 19882487] http://dx.doi.org/10.1682/JRRD.2008.09.0136

11. Corfman TA, Cooper RA, Fitzgerald SG, Cooper R. Tips and falls during electric-powered wheelchair driving: Effects of seatbelt use, legrests, and driving speed. Arch Phys Med Rehabil. 2003;84(12):1797-1802. [PMID: 14669186]

12. DiGiovine MM, Cooper RA, Boninger ML, Lawrence BM, VanSickle DP, Rentschler AJ. User assessment of manual wheelchair ride comfort and ergonomics. Arch Phys Med Rehabil. 2000;81(4):490-94. [PMID: 10768541] http://dx.doi.org/10.1053/mr.2000.3845

13. Harrison DD, Harrison SO, Croft AC, Harrison DE, Troyanovich SJ. Sitting biomechanics, part II: Optimal car driver's seat and optimal driver's spinal model. J Manipulative Physiol Ther. 2000;23(1):37-47. [PMID: 10658875] http://dx.doi.org/10.1016/S0161-4754(00)90112-X

14. ISO 2631-1. Mechanical vibration and shock. Evaluation of human exposure to whole-body vibrations. Part 1: General requirements. Geneva (Switzerland): International Organization for Standardization; 1997.

15. Wolf E, Pearlman J, Cooper RA, Fitzgerald SG, Kelleher A, Collins DM, Boninger ML, Cooper R. Vibration exposure of individuals using wheelchairs over sidewalk surfaces. Disabil Rehabil. 2005;27(23):1443-49. [PMID: 16418059] http://dx.doi.org/10.1080/09638280500264709

16. Cooper RA, Wolf E, Fitzgerald SG, Boninger ML, Ulerich $\mathrm{R}$, Ammer WA. Seat and footrest shocks and vibrations in manual wheelchairs with and without suspension. Arch Phys Med Rehabil. 2003;84(1):96-102. [PMID: 12589628] http://dx.doi.org/10.1053/apmr.2003.50069

17. VanSickle DP, Cooper RA, Boninger ML, DiGiovine CP. Analysis of vibrations induced during wheelchair propulsion. J Rehabil Res Dev. 2001;38(4):409-21. [PMID: 11563494]

18. VanSickle DP, Cooper RA, Boninger ML. Road loads acting on manual wheelchairs. IEEE Trans Rehabil Eng. 2000; 8(3):371-84. [PMID: 11001517]

http://dx.doi.org/10.1109/86.867879

19. Wolf EJ, Cooper MS, DiGiovine CP, Boninger ML, Guo S. Using the absorbed power method to evaluate effectiveness of vibration absorption of selected seat cushions during manual wheelchair propulsion. Med Eng Phys. 2004;26(9): 799-806. [PMID: 15564117] http://dx.doi.org/10.1016/j.medengphy.2004.06.005

20. DiGiovine CP, Cooper RA, Wolf EJ, Hosfield J, Corfman T. Analysis of vibration and comparison of four wheelchair cushions during manual wheelchair propulsion. Proceedings of the RESNA 2000 Annual Conference; 2000 Jun 28-Jul 2; Orlando, FL. Arlington (VA): RESNA Press; 2000. p. 242-44.

21. Fairley TE, Griffin MJ. A test method for the prediction of seat transmissibility. Society of Automotive Engineers. 1986;860046. http://dx.doi.org/10.4271/860046

22. Wei L, Griffin J. The prediction of seat transmissibility from measures of seat impedance. J Sound Vibration. 1998; 214(1):121-37. http://dx.doi.org/10.1006/jsvi.1998.1540

23. Wei L, Griffin MJ. Mathematical models for the apparent mass of the seated human body exposed to vertical vibration. J Sound Vibration. 1998;212(5):855-74.

http://dx.doi.org/10.1006/jsvi.1997.1473

24. ISO 10326-1. Mechanical vibration. Laboratory method for evaluating vehicle seat vibration. Part 1: Basic requirements. Geneva (Switzerland): International Organization for Standardization; 1992.

25. Requejo PS, Maneekobkunwong S, McNitt-Gray J, Adkins $\mathrm{R}$, Waters R. Influence of hand-rim wheelchairs with rear suspension on seat forces and head acceleration during curb descent landings. J Rehabil Med. 2009;41(6):459-66. [PMID: 19479159]

http://dx.doi.org/10.2340/16501977-0360

26. ISO 16840-2. Wheelchair seating. Part 2: Determination of physical and mechanical characteristics of devices intended to manage tissue integrity. Seat cushions. Geneva (Switzerland): International Organization for Standardization; 2007.

27. Sprigle S, Chung B, Meyer T. Assessment of the ISO impact damping test for wheelchair cushions. Assist Technol. 2010;22(4):236-44. [PMID: 21306069]

http://dx.doi.org/10.1080/10400435.2010.518581

Submitted for publication February 18, 2011. Accepted in revised form May 9, 2011.

This article and any supplementary material should be cited as follows:

Garcia-Mendez Y, Pearlman JL, Cooper RA, Boninger ML. Dynamic stiffness and transmissibility of commercially available wheelchair cushions using a laboratory test method. J Rehabil Res Dev. 2012;49(1):7-22.

http://dx.doi.org/10.1682/JRRD.2011.02.0023

ResearcherID: Yasmin Garcia-Mendez, BS: A-7497-2011

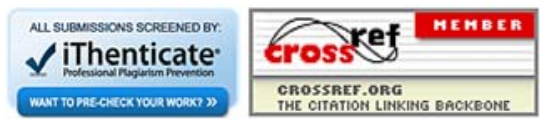


